\title{
Interactions and Signal Transduction Pathways Involved during Central Nervous System Entry by Neisseria meningitidis across the Blood-Brain Barriers
}

\author{
Julia Borkowski, Horst Schroten and Christian Schwerk*D \\ Pediatric Infectious Diseases, Department of Pediatrics, Medical Faculty Mannheim, Heidelberg University, \\ Theodor-Kutzer-Ufer 1-3, D-68167 Mannheim, Germany; julia.borkowski@medma.uni-heidelberg.de (J.B.); \\ horst.schroten@umm.de (H.S.) \\ * Correspondence: christian.schwerk@medma.uni-heidelberg.de; Tel.: +49-621-383-1299
}

Received: 10 November 2020; Accepted: 18 November 2020; Published: 20 November 2020

\begin{abstract}
The Gram-negative diplococcus Neisseria meningitidis, also called meningococcus, exclusively infects humans and can cause meningitis, a severe disease that can lead to the death of the afflicted individuals. To cause meningitis, the bacteria have to enter the central nervous system (CNS) by crossing one of the barriers protecting the CNS from entry by pathogens. These barriers are represented by the blood-brain barrier separating the blood from the brain parenchyma and the blood-cerebrospinal fluid (CSF) barriers at the choroid plexus and the meninges. During the course of meningococcal disease resulting in meningitis, the bacteria undergo several interactions with host cells, including the pharyngeal epithelium and the cells constituting the barriers between the blood and the CSF. These interactions are required to initiate signal transduction pathways that are involved during the crossing of the meningococci into the blood stream and CNS entry, as well as in the host cell response to infection. In this review we summarize the interactions and pathways involved in these processes, whose understanding could help to better understand the pathogenesis of meningococcal meningitis.
\end{abstract}

Keywords: blood-brain barrier; blood-CSF barrier; host-pathogen interaction; meningeal barrier; meningitis; Neisseria meningitidis; signal transduction

\section{Introduction}

Neisseria meningitidis, the meningococcus, is a Gram-negative diplococcus exclusively colonizing the human respiratory tract. Thus, humans are the only reservoir and transmission occurs by close contact inhaling respiratory droplets. As Gram-negative bacteria, meningococci have an outer and an inner membrane, between which a thin peptidoglycan layer is located. Meningococci are $0.6-1.0 \mu \mathrm{m}$ in diameter, with invasive strains expressing a capsule as a major virulence determinant. Further virulence factors include outer membrane proteins as pili, which extend several micrometers beyond the capsule, porins (PorA and -B), and other adhesion molecules [1]. Being a commensal, meningococci do not necessarily induce disease in the carrier. Around $10 \%$ of the European population is asymptomatically colonized by Neisseria, whereof most carrier isolates are classified nonpathogenic and noninvasive [2]. Genetic polymorphism in the host is likely to be involved in susceptibility and pathogenesis development [3,4]. Multi locus sequence typing (MLST) analyzes sequence variations in DNA fragments of a set of housekeeping genes $(a b c Z, a d k, a r o E, g d h, p d h C$, and $p g m)$ and helps to identify hypervirulent clones [5], which occur rarely, but cause the majority of disease. Additionally, a bacteriophage in disease-causing clones seems to be associated with increased neisserial virulence [6,7]. Based on the composition of the capsular polysaccharide, Neisseria serologically can be classified into 
13 serogroups (A, B, C, D, 29E, H, I, K, L, W-135, X, Y, and Z) with $90 \%$ of invasive meningococcal infections being related to serogroups A, B, C, W135, and Y $[8,9]$. Noteworthy, the distribution of meningococcal serogroups varies between countries and regions. Whereas Serogroups $C$ and $W$ are responsible for large amounts of infections in Africa and Latin America, Serogroup B predominantly accounts for disease by N. meningitidis in Europe as well as American and Western Pacific regions. Especially in Nordic countries, Serogroup $\mathrm{Y}$ is also responsible for a substantial number of cases. Generally, meningococcal disease is highest in the meningitis belt in Sub-Saharan Africa [10].

$N$. meningitidis is a leading cause of sepsis and meningitis in young children (6-24 month) and adolescents [11], and immunization is an important strategy to prevent meningococcal disease. Conjugate vaccines against Serogroups ACWY, $C$ and B are available. Whereas the vaccines against ACWY and C are based on the capsular polysaccharide, the Serogroup B vaccines (Bexsero and Trumenba) contain semiconserved surface components, since the Serogroup B capsular polysaccharide is poorly immunogenic and carries a risk of autoimmunity due to the structural similarity with the human neural cell adhesion molecule [11].

Invasive meningococcal disease (IMD) manifests as only meningitis in around $50 \%$ of cases, while other patients can suffer from sepsis, which can culminate in the Waterhouse-Friderichsen syndrome. Clinically, IMD presents with a sudden onset of malaise and unspecific symptoms such as headache, fever, chills, and nausea. Within hours, symptoms progress leading to septicemia and may be accompanied by petechiae and purpura fulminans, meningitis (vomiting and neck stiffness) or shock. Lethality due to meningococcal disease is around $15 \%$, and around $20 \%$ of survivors suffer from sequelae [11].

Pharyngeal carriage is a prerequisite for disease. Prior to meningeal inflammation, bacteria have to enter the circulation, persist in the blood with obligatory bacteremia, disseminate, and finally invade the privileged central nervous system (CNS) causing meningeal inflammation [12].

\section{Blood-Brain Barriers}

For proper function, the human brain is separated from the rest of the body by specific barriers. A schematic overview of the most relevant interfaces between peripheral tissue and the CNS is given in Figure 1. These are represented by the blood-brain barrier (BBB) localized between the blood vessels and the CNS parenchyma (Figure 1A), the blood-cerebrospinal fluid (CSF) barrier (BCSFB) at the choroid plexus separating the blood from the ventricular CSF (Figure 1B) (reviewed in $[13,14]$ ), and the meningeal barrier between the CSF-filled subarachnoidal space (SAS) and the intrameningeal blood vessels (Figure 1C) (reviewed in [12-14]). Two additional interfaces in the adult brain should be mentioned: the circumventricular organs (CVOs) barrier formed by tight junctions (TJs) between adjacent tanycytes (Figure 1D) and the inner interface between the CSF and the brain (Figure 1E) [12,14]. The CNS parenchyma (surrounded by the glia limitans) is shielded against the immune system. Ventricular and subarachnoid CSF spaces do not exhibit the same immune privileged status as the CNS parenchyma. The choroidal epithelium and the arachnoid membrane establish an outer barrier, which can be breached by immune cells in case of peripheral inflammation. In the CSF, they face antigen presenting cells (APCs), which may present antigens from the CNS. Immune cells get reactivated and penetrate the inner barrier of the glia limitans subsequently entering the brain parenchyma [13]. 
blood-brain barrier
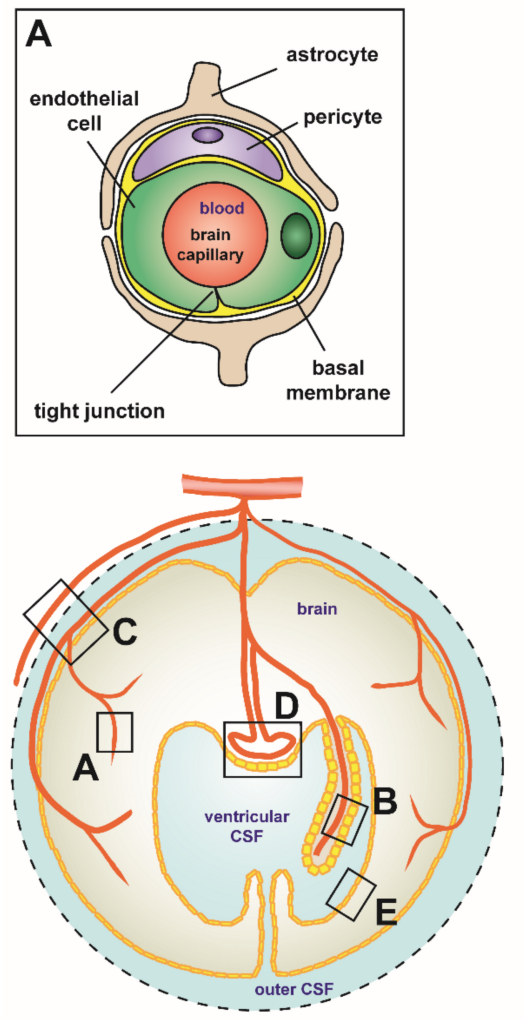

blood-cerebrospinal fluid barrier at the meninges

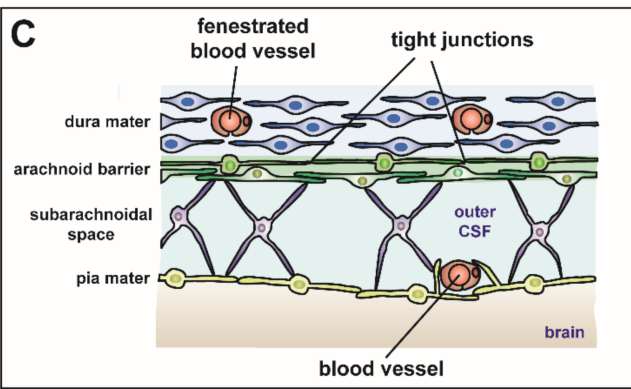

blood-cerebrospinal fluid barrier at the choroid plexus

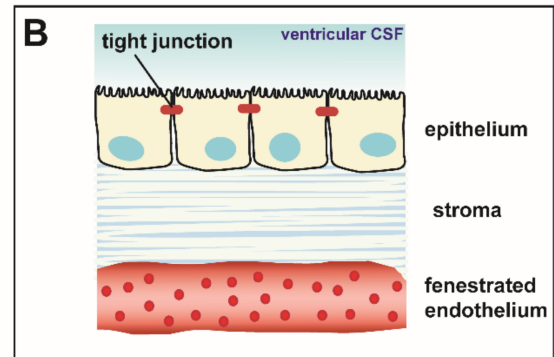

circumventricular organs

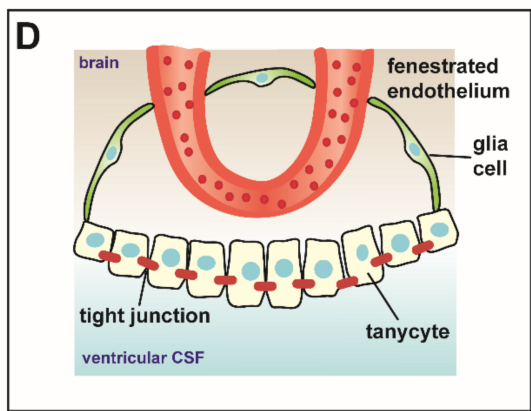

inner interface between CSF and brain

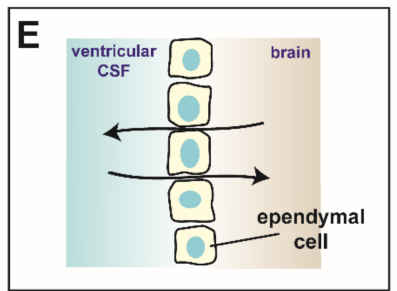

Figure 1. Interfaces between the peripheral tissue and the central nervous system (CNS). (A) The blood-brain barrier (BBB) consists of the brain microvascular endothelial cells, connected by tight junctions (TJs), in conjunction with astrocytes and pericytes, and separates the brain parenchyma from the blood. (B) The choroid plexus, which is located in the ventricular system, is highly vascularized by a fenestrated endothelium that is placed in the stroma. At the choroid plexus, the blood-cerebrospinal fluid (CSF) barrier (BCSFB) is formed by epithelial cells connected by TJs and separates the blood from the ventricular CSF. (C) At the meninges, the dura mater contains fenestrated blood vessels. The arachnoid mater is located adjacent to the dura mater and encloses the subarachnoidal space (SAS) that contains the outer CSF. The BCSFB barrier function of the meninges is formed by the cells of the arachnoid mate, which are connected by TJs. Furthermore, a BCSFB barrier function can be postulated for endothelial cells of pial vessels, which cross the SAS and merge into brain capillaries, but are not covered by pericytes and astrocytic endfeets. (D) The blood vessels of the circumventricular organs (CVOs) are fenestrated. The barrier towards the ventricular CSF is formed by TJs between adjacent specialized ependymal cells, termed tanycytes. Glia cells (with TJs) shield against the brain parenchyma. (E) Ependymal cells lining the ventricles separate the ventricular CSF from the brain parenchyma. This figure is adapted from [14]. 


\subsection{Blood-Brain Barrier}

Prerequisite for BBB function is a complex interplay of several components based on the neurovascular unit composed of brain endothelium, pericytes, astrocytes, and the basal membranes (Figure 1A).

Brain endothelial cells are characterized by very low pinocytosis rates due to suppression of vesicular activity. However, brain homeostasis ensuring nutrient supply via the blood into the CNS and removal of toxic agents via the contrary direction is maintained by specific membrane transporters, such as glucose transporter 1 (GLUT1) and P-glycoprotein (Pgp) [15]. Free diffusion of ions and molecules via the paracellular route is mostly prevented by TJs closely connecting brain endothelial cells. In parallel, TJs prevent diffusion of proteins within the lipid bilayer and thereby determine cellular polarity. TJs represent a composition of transmembrane proteins, cytoplasmic scaffolding proteins linking the former with the actin cytoskeleton, and signaling proteins. For a long time, the transmembrane proteins claudin-1, claudin-3, claudin-5, claudin-11, and claudin-12 have been considered as relevant TJ components at the BBB, but, due to controversies in several studies, claudin- 5 is the only claudin whose expression remains commonly confirmed [16]. Occludin, tricellulin, and MARVEL domain-containing protein 3 (MARVELD3) belong to the tight junction-associated MARVEL protein (TAMP) family and represent a second group of junctional transmembrane proteins. Occludin is likely to be involved in regulating TJ stability and barrier function, but less in TJ assembly. Tricelliulin, as indicated by its name, is localized at tricellular junctions, and its precise function at endothelial TJs remains to be clarified. Junction adhesion molecule (JAM) proteins, a third transmembrane protein group containing JAM-A, JAM-B, and JAM-C, interact with cytoplasmic proteins, thereby providing the linkage to the actin cytoskeleton. JAM proteins regulate cell polarity by interacting with the polarity complex protein Par3. Scaffolding proteins (Membrane-associated guanylate kinase (MAGUK) proteins), such as zonula occludens (ZO) 1 and $\mathrm{ZO} 2$, connect TJ transmembrane proteins to the cellular cytoskeleton by binding to F-actin. ZO1 is also involved in adherens junction (AJ) assembly, junctional complexes required for $\mathrm{TJ}$ formation. In $\mathrm{AJ}$, the intracellular domain of the transmembrane protein vascular endothelial cadherin (VE-cadherin) engages p120 catenin and $\beta$-catenin. The anchor protein $\alpha$-catenin acts as a bridge connecting VE-cadherin with the cytoskeleton by binding to vinculin and ZO1. The nectin-AF-6 complex also contributes to endothelial AJ formation. Platelet endothelial cell adhesion molecule-1 (PECAM-1) belonging to the Ig family is highly expressed at interendothelial junctions maintaining junction integrity [16]. Due to the tight endothelial lining at the BBB, a high transendothelial electrical resistance is generated across the endothelial vessel wall, reaching more than $1500 \Omega \mathrm{cm}^{2}$ in capillaries of rats [17].

The luminal side of the vessel wall is lined by a glycocalyx composed of a carbohydrate-rich mesh of anionic polymers representing already a first line of barrier for blood borne pathogens. The basolateral cell side faces the endothelial basement membrane composed of extracellular matrix (ECM) proteins (a network of type IV collagen, $\alpha 4$ and $\alpha 5$ laminins, nidogen, heparan sulfate proteoglycans and some glycoproteins) secreted by both endothelial cells and pericytes. The basement membrane includes embedded pericytes (endothelial cell/pericyte ratio between 1:1 to 3:1), together with smooth muscle cells covering the endothelial cells, and builds the tunica media. Unique to brain endothelial cells is a second basement membrane, which includes $\alpha 1$ and $\alpha 2$ laminins secreted by adjacent astrocytes, and is named parenchymal basement membrane. Together with astrocytic endfeet, the parenchymal basement membrane represents a thin physical barrier, the glia limitans. At the level of post-capillary venules, a small space is generated between the two membranes called perivascular space. At the capillary level, the two membrane leaflets merge inseparably (the BBB structure has recently been reviewed in [16]).

Most studies of pathogens penetrating the CNS via the endothelial route focus on brain microvascular endothelial cells exhibiting a tight barrier. Endothelial cells of brain post-capillary venules and of subpial and subarachnoidal veins located in close vicinity to the SAS, however, exhibit less barrier function than the endothelial cells of the brain parenchyma. Due to their "leaky" 
interendothelial junctions, they are more likely to be the primary site of passage of pathogens into the CSF [18]. In the case of passing through subpial and subarachnoidal veins, the bacteria face the meningeal barrier, whose structure and interaction with meningococci is further addressed below.

\subsection{Blood-Cerebrospinal Fluid Barrier at the Choroid Plexus}

The BCSFB faces circulating fluids on both sides, the blood on the basolateral side and the CSF on the apical side. The barrier itself is formed by choroidal epithelial cells, which surround a highly vascularized stromal tissue, together inclosing the CSF-filled ventricles (Figure 1B). Four choroid plexus exist in the brain being located at the two laterals and the third and fourth ventricles [13].

The choroid plexus epithelial cells secrete vascular endothelial growth factor (VEGF), thus controlling formation and maintenance of endothelial fenestrae (involving plasmalemma vesicle-associated protein (Plvap)). Fenestration allows blood components to easily get in contact with the stromal tissue. Additionally, the epithelial cells produce CSF. Consistently with being located at the interface of two fluids, cells exhibit basolateral infoldings as well as apical microvilli, thereby increasing the surface area and allowing substantial exchange [13]. Transport processes across the barrier, however, are strictly regulated. ABC transporters as well as solute carrier (SLC) transporters monitor the return of lipophilic molecules back to the blood and the transport of ions and amino acids into the CSF, respectively. Claudin-2 and aquaporin 1 ensure paracellular and transcellular water flow from blood to the CSF. Paracellular permeability across the epithelial cells is limited due to the presence of TJ complexes localized at the apical lateral cell side. AJ are localized basolaterally of TJ. Together both junctional complexes determine cellular polarity [16].

Due to the junctional sealing, choroidal epithelial cells produce a strong transepithelial electrical resistance (TEER), which, however, is lower than TEER values generated at the BBB. AJs at the $\mathrm{BCSFB}$ are composed similar to the BBB with epithelial cadherin (E-cadherin) replacing VE-cadherin. E-cadherin binds to p120- and $\beta$-catenin, which in turn bind to $\alpha$-catenin linking E-cadherin to the actin cytoskeleton. Several claudins (claudin-1, claudin-2, claudin-3, claudin-9, claudin-10, claudin-11, and claudin-19) have been reported to be expressed at the choroid plexus TJs. Occludin and ZO-1 as well are involved in TJ formation. JAM-A and JAM-C, only at the choroid plexus of the fourth ventricle, are present at the TJs at the BCSFB. Similar to endothelial TJ complexes, several studies report controversial results, thus the contribution of each component requires ongoing clarification. Recently, a protein called Alix has been shown to be highly expressed at the TJ at the BCSFB, leading to massive tight junctional disorganization and hydrocephalus, if absent $[13,16]$.

Due to its strategic interfacial localization, the choroid plexus integrates signals from both the blood and the brain, and dynamically responds via modulation of its transcriptome, proteome, and secretome acting as an important sensor of changing conditions or stimuli. Furthermore, the choroid plexus has an important role during neuroimmune surveillance and is associated with several types of immune cells of both, the adaptive and innate immunity. Epiplexus Kolmer cells reside on the apical/CSF-facing side. On the vascularized stromal/basolateral side, major histocompatibility complex (MHC) class II expressing macrophages, dendritic cells, and myeloid progenitor cells are located directly being exposed to blood components. In contrast to the CNS parenchyma, which is free from cells of the adaptive immune system, 150,000-750,000 immune cells are present in the CSF, mostly representing T-memory cell populations. Additionally, those immune cells likely enter the CNS via the choroid plexus route, thus the choroid plexus holds an important role in regulating the balance of immune cell trafficking into the CNS during immune surveillance and CNS pathology (choroidal BCSFB structure and function have recently been reviewed in $[13,16])$.

\subsection{Blood-Cerebrospinal Fluid Barrier at the Meninges}

The meninges cover the CNS, brain, and spinal cord. The dura mater is the most peripheral part facing the skull bone composed of dense collagen fiber bundles containing arteries, veins, and lymphatics. Located adjacent to the dura is the arachnoid mater enclosing the underlying CSF-filled 
SAS (Figure 1C). Trabeculae, which represent collagen bundles coated by leptomeningeal cells, extend from the inner arachnoid layer across the SAS to join the pia mater or suspending subarachnoid blood vessels in the SAS. The pia mater is the most inner part tightly facing the brain parenchyma and closely surrounding vessels following their way penetrating the CNS parenchyma. Together, pia and arachnoid mater form the leptomeninges composed by leptomeningeal cells. The BCSFB barrier function of the meninges is strictly formed by the arachnoid mater, shielding the CSF from dural vessels, which exhibit fenestrae. Thus, leptomeningeal cells of the outer layer of the arachnoid, where it abuts the dura, are connected by TJ. Desmosomes join leptomeningeal cells of the arachnoidea main body and less frequently of the pia. Pial cells coating trabeculae, arteries, and veins in the SAS are connected by small gap junctions. Given the fact that bacterial meningitis predominantly represents an inflammation of the leptomeninges, this barrier may play a more relevant role than supposed to $[19,20]$. An additional BCSFB barrier function can be postulated for the endothelial cells of pial vessels crossing the SAS following penetrating arterioles and merging into brain capillaries, thus representing a continuity with the microvascular endothelial cells of the BBB (meningeal BCSFB structure has been reviewed in $[12,16])$. However, the pial endothelium is not covered by pericytes and astrocytic endfeets.

Similar to the choroid plexus, the arachnoid contributes to CNS immunity regulation due to a high number of MHC class II expressing myeloid cells strategically positioned on both sides of the membrane. On the dura-facing side, macrophages and dendritic cells are located, and the CSF-facing side harbors resident macrophages working as scavenger and possibly presenting antigens to entering T-cells [13].

\section{Neisserial Interactions with the Host}

\subsection{Colonization as a Prerequisite for Meningococcal Disease}

A prerequisite for meningococcal CNS entry is bacteremia. Since IMD commonly manifests as meningitis or fulminant sepsis, bacteremia during meningococcal meningitis pathogenesis seems to be asymptomatic [12]. Once transferred to a new host, meningococci get in contact with the human nasopharyngeal epithelium. Initially, only a few individuals attach to the epithelial cells. Microcolonies with a high number of interacting bacteria develop by bacterial replication [18]. As the human respiratory tract is the only natural reservoir of meningococci, dissemination to new colonization sites within the same host or to a new host takes its run from here. A regulated detachment process releasing individual bacteria from microcolonies favors their dissemination. As shown in vitro with human cell lines, the underlying mechanism is based on a posttranscriptional modification during which a transferase adds phosphoglycerol to type IV pili (Tfp). Thereby, the Tfp dependent interbacterial contacts in the bacterial aggregations are limited and dissemination is promoted [21]. Initial attachment at the new colonization site of human cells or organ cultures in vitro is also mediated by meningococcal Tfp [22-26], the most important adhesins of encapsulated strains passing through the capsular polysaccharide and extending from the bacterial surface. Other adhesins remain concealed by the capsule.

CD46, a regulatory protein of the complement system, has been identified as an epithelial surface receptor for pilated meningococci in vitro [27]. Additionally, a human CD46 transgenic mice model demonstrated that upon intranasal challenge those mice were susceptible to IMD, since the bacteria could cross the BBB efficiently [28]. However, inconsistent with CD46 being a primary Tfp receptor during adhesion is its basolateral expression $[29,30]$. Due to several other controversies the role of CD46 during meningococcal pathogenesis remains still unclear [31-34].

Tfp dependent adhesion to human epithelial cell lines in vitro elicits rapid localized rearrangements in the cellular cortex, which are accompanied by the formation of specific molecular complexes, called cortical plaques, underneath the attached bacterial colonies. These structures result from the re-localization of specific proteins in the plasma membrane, including components of the 
cortical cytoskeleton and integral membrane proteins. Thus, the Tfp contact induces localized actin polymerization and the recruitment of ezrin, the second cortical cytoskeleton component, from microvilli-like protrusions to the attachment sites. Ezrin serves as a linker between the actin cytoskeleton and transmembrane proteins and subsequently promotes the recruitment of Ezrin binding proteins, which are redistributed from their original localization, mainly at cell protrusions and at lateral cell-cell junctions, to form clusters beneath bacterial attachment sites [35,36].

In human pharyngeal organ cultures the localized actin polymerization leads to the formation of microvilli-like protrusions closely accommodating the bacterial colonies and in consequence to their internalization [37]. Following this initial Tfp-dependent adhesion step, bacteria get in close contact (intimate adhesion) with the host cell. To enable intimate adhesion, pili get retracted and bacteria become tightly associated with the host membrane, as shown with human epithelial cells in vitro [22]. Microvilli disappear during intimate adhesion and the cell surface becomes denuded from microvilli at the bacterial attachment sites, while meningococci at the actin polymerization sites remain present. Thus, Tfp may act as sensors, mediating initial cell contact, but upon contact get downregulated. Upon contact with human epithelial cells in vitro, capsule synthesis is also repressed, as the capsule may hinder intimate adhesion as well, thereby unmasking surface structures that may be involved in intimate adhesion [38]. Upon this intimate contact, meningococci may cross the epithelial respiratory barrier following a transcellular route involving the microtubule network without affecting barrier integrity. Initial capsule and Tfp expression, however, is required for crossing and capsular expression is important for intracellular survival in vitro [34,39]. With the crossing of the nasopharyngeal barrier and meningococci reaching the blood stream, carrier status is left and pathology begins.

However, meningococci may not necessarily have to use the blood circulation to reach the meninges. An alternative route has been described for intranasally infected mice that revealed epithelial lesions and junctional alterations at the nasal epithelium in particular at the olfactory epithelium, upon infection. The bacterial distribution suggested that meningococci directly passed from the nasopharynx to the meninges via the olfactory nerve system [40].

Minor Adhesins and Invasins Involved during Interaction with Epithelial Cells

Capsule downregulation unmasks minor adhesins and invasins, such as the opacity proteins Opc and Opa as well as NadA (involved in adhesion/invasion to/in epithelial cells), NhhA and App (autotransporters involved in adhesion to epithelial cells), and MspA (autotransporter involved in adherence to epithelial and endothelial cells) that together with App has been shown in vitro to be transported to the nucleus, where it proteolytically cleaves the core histone H3 [41], and HrpA (two partner secretion system) that might be involved in adhesion to epithelial cells [42].

Opa are classified into two categories. A small group of variants bind to heparin sulfate proteoglycans (HSPGs) and ECM proteins (fibronectin and vitronectin), most variants, however, bind to carcinoembryonic antigen-related cell adhesion molecules (CEACAMs). In contrast to CEACAMs, HSPG receptors are not expressed on the apical surface of polarized epithelia, such as the nasopharyngeal epithelium, thus interaction with HSPG receptors is not involved in apical adherence [42]. As described, pilus retraction upon initial attachment mediates intimate contact favoring interaction of Opa and apical expressed CEACAM leading to engulfment and transcytosis thereby entering subepithelial spaces. CEACAM1-triggered penetration of Opa-expressing meningococci of the nasopharyngeal epithelium was also confirmed in a CEACAM1-humanized mice model [43]. Binding to CEACAM may also suppress toll-like receptor 2 (TLR2)-dependent innate responses in epithelial cells by bacterial trapping. Thereby, TLR2 initiated, NFkB-dependent inflammatory responses are reduced, as shown in in vitro cultures of human primary bronchial epithelial cells obtained from normal human volunteers [44]. Interaction with CEACAMs may further affect several immune functions (CEACAM Opa interaction has been reviewed in [42]). 
Opc can interact with epithelial cell lines in vitro via HSPGs, without the need of human serum factors vibronectin and fitronectin as described for Opc-dependent binding to endothelial cells, inducing signaling and subsequent internalization [45-47].

\subsection{Neisserial Survival in the Blood}

Meningococci have evolved several strategies to evade innate immune defense in the blood. Besides the expression of several factors that favor their survival in the blood (TspB [48], TbpAB [49], LbpAB [50,51], HpuAB [52], HmbR [53], NHBA [54], Ig-binding protease [55], PorA [56], NspA nd PorB3 [57], fHbp [58], and others [59,60]), strategies are mostly based on modulation of surface components. The capsular polysaccharide and lipopolysaccharide (LPS) exhibit characteristic antigenic variation enabling meningococci to avoid antibody deposition, complement-mediated killing, and phagocytosis [12]. Horizontal gene transfer (intragenomic recombination due to natural competence) in the capsule operon can provoke capsule switching [61-63]. In addition, exchange of genetic alleles (intergenomic recombination of gene segments due to availability of several gene copies in the genome) in the opa genes $[64,65]$ or pil genes $[66,67]$ creates new variants. Antigenic variation can additionally be achieved by phase variation. Addition or reduction of repetitive sequences due to single strand mispairing (ssm) during replication can modulate expression levels $[68,69]$. Ssm outside the open reading frame $(\mathrm{ORF})$ can affect transcriptional efficiency as well as posttranslational events or binding of regulatory proteins. Ssm inside the ORF may result in on/off switching of genes such as the capsule [70], LPS [71] or opa genes [72]. Reversible exchange of mobile insertion elements inside the siaD gene also effects capsule variation [73].

Besides variation, evasion can also be achieved by molecular mimicry of host structures due to the addition of sialic acid to the capsular polysaccharide [74] or the LPS [71,75]. The serogroup B capsule itself is already poorly immunogenic due to the structural similarity to the human neural cell adhesion molecule [11]. Furthermore, posttranslational modification by attachment of phosphorylcholine may enable interaction with the PAF-receptor and is likely to be involved in immune evasion as well [9].

Vascular colonization of peripheral vessels that play a relevant role during meningococcal induced purpuric skin lesions proceeds in the same way as is described for cerebral endothelial cells below [76-79].

\subsection{Neisserial Interactions with the Host during CNS Entry}

Via the blood stream, the bacteria reach the anatomical structures described in Figure 1. The most relevant barriers during CNS invasion by N. meningitidis are the BBB, the BCSFB at the choroid plexus, and the BCSFB at the meninges. The interactions of meningococci with host cells at these barriers and the signaling pathways involved are discussed in the following.

\subsubsection{Neisserial Interactions with the Blood-Brain Barrier}

Endothelial cells of the BBB (Figure 1A) have been prevalently considered to be the primary entry site of meningococci into the CNS with a possible draining into the SAS via the glymphatic pathway $[18,80]$. The bacteria engage in first contact with the luminal side of the brain microvasculature. Several in vitro models have been established to study meningococcal interaction with brain endothelial cells [81]. A humanized mouse model implanted with human skin containing human dermal vessels has been established to analyze interaction with dermal microvascular cells [82], which has been shown to be similar to cerebral microvascular cells [76].

The steps participating during adhesion of $N$. meningitidis to endothelium are summarized in Figure 2. The host cell receptor responsible for initial meningococcal attachment to both, peripheral and cerebral, endothelium has been remained obscure for a long time. Several receptors have been reported to be the Tfp interacting receptor such as CD46 [27,28,31,33], the Laminin receptor [83], or the platelet activating factor receptor (the latter, however, on human epithelial airway cells) [84]. Recently, however, CD147, a member of the immunoglobin superfamily expressed on brain capillaries, has been 
identified to be a critical receptor for Tpf (PilV and PilE)-dependent adhesion. Receptor interaction has been verified in vitro to human brain and peripheral endothelial cells and to induced pluripotent stem cell-derived brain endothelial cells, in vivo in a mice model with xenografted human skin containing dermal microvasculature, and ex vivo in human brain tissue explants $[77,85]$.

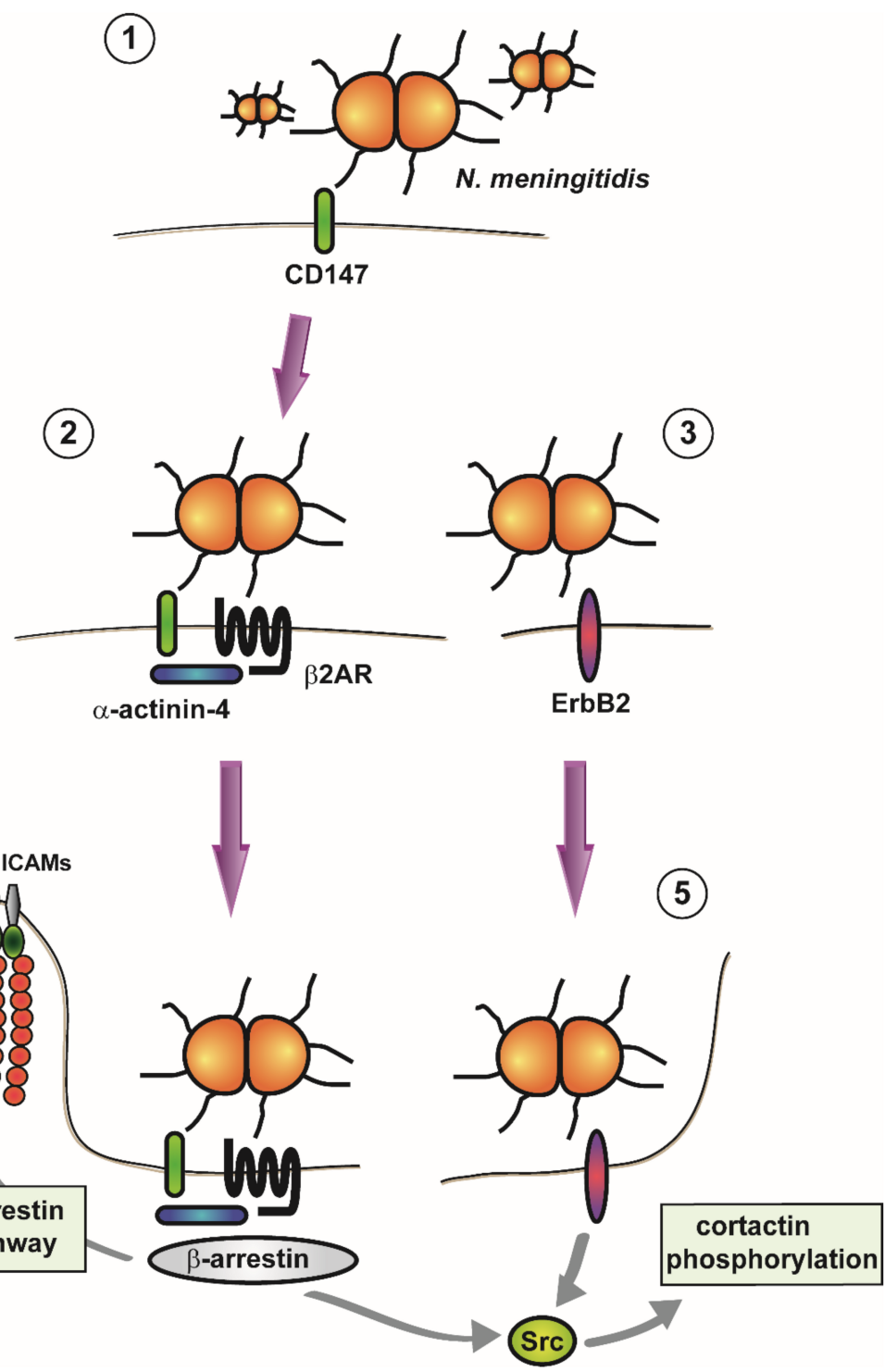

Figure 2. Adhesion of Neisseria meningitidis to the endothelium. (1) In an initial step, meningococci adhere to the immunoglobulin superfamily member CD147 on the surface of host cells. (2) Subsequently, the $G$ protein coupled $\beta 2$-adrenergic receptor ( $\beta 2 A R$ ) forms heteromeric complexes with CD147 that are stabilized by $\alpha$-actinin-4. (3) Adhesion of N. meningitidis also leads to the recruitment of the ErbB2 receptor. (4) Activation of $\beta 2 \mathrm{AR}$ in return causes activation of the $\beta$-arrestin pathway, leading to plasma membrane remodeling and the recruitment of ERM proteins (Ezrin and Moesin), together with ERM-binding transmembrane proteins (CD44 and ICAMs) and cortical actin (cortical plaque formation). Src is also recruited and activated. (5) Association of N. meningitidis with ErbB2 leads to recruitment and activation of Src, which in turn causes phosphorylation of cortactin (which triggers the formation of membrane protrusions).

As shown in vitro using endothelial cell lines, consecutively upon the initial adhesion to CD147 the $G$ protein coupled $\beta 2$-adrenergic receptor $(\beta 2 A R)$ is recruited beneath meningococcal colonies and both receptors form highly ordered heterooligomeric complexes scaffolded by $\alpha$-actinin- 4 increasing 
the binding strength of meningococci under shear stress [86]. Activation of $\beta 2 \mathrm{AR}$ in a Tfp dependent manner results in the activation of the $\beta$-arrestin pathway with a local remodeling of the plasma membrane due to the recruitment of ezrin and moesin (ERM proteins), as well as ERM-binding transmembrane proteins, such as CD44, ICAM-1/-2, cortical actin, and the activation of the Rho GTPases (Rho and Cdc42) [87,88]. Src kinase is also recruited and activated [88,89]. Together, these events lead to the formation of specific protein clusters (cortical plaques) accompanied by local actin polymerization, finally promoting the formation of membrane protrusions highly enriched in the recruited proteins at the bacterial attachment sites [88]. Those microvilli-like protrusions stabilize the colonies and protect them against hemodynamic forces. Ezrin recruitment and sheer stress resistance are based on the presence of PilV [90]. A genetic polymorphism in the $\beta 2 A R$ has been identified to be associated with increased susceptibility to bacterial meningitis [3].

Most of the transmembrane proteins, which are sequestrated in the cortical plaques at neisserial attachment sites, are key players in leukocyte adhesion and guidance including CD44, ICAM-1, and VCAM-1. Their titration towards bacterial colonies prevents the formation of leukocyte docking structures resulting in reduced leukocyte contacts and their subsequent diapedesis. Consequently, in a human bone marrow endothelial cell line, Neisseria downregulates the inflammatory response upon infection by interfering with leukocyte-endothelial interaction [91].

Work with primary endothelial cells and endothelial cell lines has shown that Tfp-mediated adhesion also induces ErbB2 receptor recruitment to attachment sites and its subsequent phosphorylation $[76,92,93]$. Active ErbB2 recruits Src kinase and results in its subsequent activation, which in turn leads to the phosphorylation of cortactin triggering the formation of protrusions [93]. ErbB2 is recruited to the site, where cortical plaques develop, but the ErbB2/src pathway is not involved in their formation (ezrin recruitment and actin polymerization). Ezrin recruitment occurs independent of Rho and Cdc42 [87]. Actin and cortactin polymerization, however, depend on Rho and Cdc42 activation $[87,93]$. Bacterial internalization is only partially affected upon Rho and Cdc42 inhibition [93], suggesting that the bacteria-induced reorganization of the actin cytoskeleton in cooperation with the ErbB2/Src and the GTPase dependent signaling pathway results in an efficient bacterial internalization [93]. ErbB, $\beta$-arrestin, and integrin signaling can activate the mitogen-activated kinase (MAPK) pathways in vitro [94,95], which have been shown to be activated upon neisserial infection affecting internalization and cytokine release in a human brain microvascular endothelial cell line [96]. Phosphoinositide3-kinase/Rac1 signaling dependent cortactin recruitment triggered by LPS has also been reported to be involved in meningococcal invasion of endothelial cells in a human bone marrow endothelial cell line [97].

In endothelial cell lines, protrusional engulfment of meningococci can lead to internalization into intracellular vacuoles [87]. Similarly, subsequently to invasion into human brain microvascular endothelial cells, meningococci are found inside of Neisseria-containing vacuoles [98]. These vacuoles correspond to early and late endosomal and/or lysosomal compartments as demonstrated by colocalization with the transferrin receptor and LAMP-1, respectively. The bacteria replicate in the vacuoles and are protected by the capsule. It has been suggested that internalization into intracellular vacuoles and the intracellular replication could play a role during barrier crossing $[87,98]$. However, determination of the mechanisms during a putative transcellular crossing of the BBB by meningococci requires further investigation.

Despite the data pointing to a transcellular route through endothelial cells, there is also evidence that meningococci cross the endothelium using the paracellular route via gaps between cells due the delocalization of junctional proteins (AJ proteins such as VE-cadherin, p120 catenin, and $\beta$-catenin as well as TJ proteins such as ZO1, ZO2, and claudin-5). Results in human brain microvascular endothelial cell lines show that this event could occur upon the Tfp-dependent recruitment of the polarity complex (Par3/Par6/PKC ל) underneath meningococcal colonies. Polarity complex recruitment is induced by binding of N. meningitidis to host cell receptors, followed by recruitment of ezrin, clustering of transmembrane proteins and activation of the GTPase Cdc42. Tearing apart the proteins 
from the junctional complexes and sequestrating them at the attachment sites leads to an increased barrier permeability that promotes a paracellular crossing of the BBB [99]. Activation of Matrix Metalloprotease (MMP) 8 proteolytically cleaving occludin, an endothelial TJ protein, as well as favors opening of the paracellular route for meningococcal crossing of the BBB [100].

Besides cellular reorganization based on intracellular protein interactions upon infection, human brain microvascular endothelial cells exhibit an adjusted transcriptional profile when infected with $N$. meningitidis in vitro. A transcriptional increase of genes encoding for proteins involved in bacterial adhesion and invasion, apoptosis, and cell adhesion, as well as in downstream signaling of integrins and corresponding negative regulators has been observed. In addition, genes involved in cytoskeleton reorganization are regulated. Almost $50 \%$ of the regulated genes depend on capsule expression [101].

During fulminant meningococcal disease with purpura fulminans, meningococci not only adhere and cross brain endothelial cells, but also breach the vascular wall of peripheral endothelial cells, leading to the characteristic hemorrhagic lesions of the skin, as shown in a model employing human skin grafted SCID mice [78]. Recruitment of the polarity complex finally opening cell-cell contacts by tearing away the junctional proteins has been shown to be a common feature upon neisserial infection in primary peripheral and cerebral endothelial cells [76].

Penetration of the nasopharyngeal epithelium and the endothelium in the periphery and at the $\mathrm{BBB}$, however, involves two different signaling pathways [76]. This can be explained by the different local ambient conditions (normally slow shear stress in the nasopharynx besides coughing, and varying, but steadily existent, shear stress in the blood) and the intention behind the colonization of the respective niche (crossing of the nasopharyngeal barrier/spreading to new attachment sites, and crossing of peripheral and cerebral endothelial barriers/vascular colonization against shear stress) [76,102]. Common and differing features in signaling induced upon the attachment of meningococci to epithelial and endothelial cells are displayed in Table 1.

Table 1. Features common and differing in signaling pathways induced upon meningococcal attachment to epithelial and endothelial cells.

\begin{aligned} & \hline Nasopharyngeal Epithelium \multicolumn{1}{c}{ Peripheral and Cerebral Endothelium } \\ & \hline - Formation of cortical plaques $[35,87,88] \\ &$ - Recruitment of ezrin $[35,87,88] \\ &$ - Accumulation of actin $[22,87] \\ &$ - Recruitment of adhesion molecules $[35,87,88] \\ &$ - Recruitment of membrane receptors $[35,87,88] \\ &$ - Recruitment of $\beta 2 A R[76,88] \\ &$\hline\end{aligned}

- No significant recruitment of the polarity complex (Par3/Par6) beneath colonies [76]

- No alteration delocalization and colocalization with ezrin under colonies of TJ (ZO1) and AJ proteins (p120 catenin, E-cadherin) [76]

- $\quad$ Transcellular barrier crossing $[22,34]$
Recruitment of the polarity complex (Par3/Par6) beneath attached colonies colocalizing with cortical plaques [99]

Recruitment of junctional components (AJ: VE-cadherin, p120 catenin, and $\beta$-catenin; and TJ: $\mathrm{ZO} 1, \mathrm{ZO} 2$, and claudin-5) under the attached microcolonies [99]

Formation of gaps between the cells promoting paracellular barrier crossing [99] Activation of $\beta$-arrestin pathway upon adhesion [88]

- $\quad$ No activation of the $\beta$-arrestin pathway [76] 
Table 1. Cont.

\begin{tabular}{ll}
\hline \multicolumn{1}{c}{ Nasopharyngeal Epithelium } & \multicolumn{1}{c}{ Peripheral and Cerebral Endothelium } \\
\hline $\begin{array}{l}\beta \text {-arrestin signaling pathway independent } \\
\text { formation of cortical plaques [76] }\end{array}$ & $\begin{array}{l}\beta \text {-arrestin signaling pathway is essential for the } \\
\text { formation of cortical plaques [88] }\end{array}$ \\
\hline $\begin{array}{l}\text { no involvement of Src kinase in cortical plaque } \\
\text { formation and actin polymerization [76] }\end{array}$ & $\begin{array}{l}\text { Recruitment of Src kinase below the attached colonies, } \\
\text { Src involvement in formation of cortical plaques, and } \\
\text { actin polymerization [76] }\end{array}$ \\
\hline $\begin{array}{l}\text { protrusions do not mediate protection against } \\
\text { shear stress [76] }\end{array}$ & $\begin{array}{l}\text { protrusions stabilize the colonies and protect them } \\
\text { against blood flow generated shear stress [90] }\end{array}$ \\
\hline induction of signaling is PilV independent [76] & $\begin{array}{l}\text { Activation of the } \beta \text {-arrestin pathway is PilV (and PilE) } \\
\text { dependent; Ezrin recruitment, cortical plaque, and } \\
\text { shear stress resistance are PilV dependent [90] }\end{array}$ \\
\hline
\end{tabular}

Pilated and encapsulated phenotypes are isolated from blood and CSF [12]. Minor adhesins located in the outer membrane are mostly concealed due to their subcapsular localization. A possible scenario similar to colonization of the nasopharyngeal epithelium would include retraction of Tfp and a concomitant downregulation of the capsule, thereby exposing adhesins and ensuring a close contact [12]. Recently, several thus far unknown potential meningococcal ligands interacting with human brain microvascular endothelial cells have been recovered and identified upon infection [103]. Non-Tfp-mediated interactions become relevant in vitro under inflammatory conditions or during receptor clustering, both cases leading to a high degree of receptor density [104-108].

Thus far, the most prominent role during endothelial interaction probably is probably played by the subcapsular invasin Opc that in vitro interacts with the extracellular matrix proteins vitronectin and fibronectin $[105,109,110]$, which occur abundantly in human serum. However, it preferentially binds to sulfated tyrosine residues of the activated form of human vitronectin, but not to native vitronectin [110]. Via a sandwich mechanism with vitronectin and fibronectin acting as molecular bridges, Opc binds to integrins ( $\alpha \mathrm{V} \beta 3$-integrin/vitronectin and $\alpha 5 \beta 1$-integrin/fibronectin) on the apical surface of endothelial cells. Thereby, meningococci are linked to the integrins subsequently leading to the formation of a trimolecular complex $[105,109]$. Integrin signaling is dependent on adapter molecules, such as protein tyrosine kinases, due to their lack of intrinsic enzymatic activity [111]. In a human brain microvascular endothelial cell line, Src kinase has been shown to be activated Opc-dependently, linking the cytoplasmatic integrin tails to the actin cytoskeleton promoting the meningococcal uptake by actin rearrangements [112]. In addition to Src, Opc-dependent meningococcal internalization depends on focal adhesion kinase (FAK) and cortactin [113]. Once internalized Opc can interact in vitro with the intracellular cytoskeletal protein $\alpha$-actinin, a modulator of signaling pathways and cytoskeletal functions, thereby facilitating the passage across endothelial barriers [114]. Opc is suggested to be relevant for crossing of cerebral endothelial cells, since Opc-lacking strains of the ET-37/ST11 clonal complex can affect clinical disease profile in being more virulent to cause serious septicemia than meningitis [68,105,115-117].

Opc and Opa can not only function as adhesins/invasins, but also act as cyclomodulins, known to hijack cell cycle check points, to establish bacterial infection. In human brain endothelial cells in vitro, meningococcal infection reveals an accumulation of brain endothelial cells in the S-phase (DNA replication) in parallel with a decrease of cells in G2/M phase (gap preparing cells for division/mitosis) leading to cell cycle arrest [118]. Cell cycle arrest has also been observed in nasopharyngeal epithelial cells in vitro. However, epithelial cells exhibited an arrest in G1-phase (gap between DNA replication and mitosis), which manifested in an accumulation of those cells in G1. In both brain endothelial and nasopharyngeal epithelial cells, cell arrest correlated with an accumulation and increased nuclear 
localization of CKI p21 ${ }^{\text {WAF1/CIP1 }}$ a cell cycle inhibitor, known to slow cell cycle and to induce cell cycle arrest in G1-, G2-, or S-phase when overexpressed [118,119].

Additionally, Opc is required to induce specialized ceramide-enriched membrane domains, which provide a proper receptor and signaling molecule clustering. Opc expressing meningococci bind to HSPGs followed by activation of phosphatidylcholine specific phospholipase C (PC-PLC), leading to the activation of acid sphingomyelinase (ASM) in human brain microvascular endothelial cell lines. ASM metabolizes sphingomyelin into ceramide and phosphorylcholine. Ceramide release results in the formation of ceramide-enriched raft domains, trapping receptors and signaling molecules such as ErbB2 and cortical plaques proteins, thereby favoring bacterial entry [120].

\subsubsection{Neisserial Interactions with the Blood-Cerebrospinal Fluid Barrier at the Choroid Plexus}

In contrast to interactions of meningococci with the BBB, interactions with the BCSFB at the choroidal epithelial cells have been less investigated, likely due to the fact that meningococci exclusively interact with human cells and the lack of appropriate human BCSFB models. The development of those models is definitely of high relevance, since in a previous case of fulminant meningococcemia meningococci were found in particularly high numbers adhering to endothelial cells of capillaries of the choroid plexus and to a lesser extent to endothelial cells of capillaries of the meninges. Since the patient died early during disease progress before an acute inflammation of the meninges, but bacteria could already be recovered from the CSF, it was likely to find bacteria still attached to the structures they used for their entry [121]. This can be a problem when disease has progressed, since bacteria have spread and secondary effects cannot be excluded. However, the relevance of the choroid plexus as a CSF entry route often is understated with the argument that no bacteria were found adhering to or between the choroidal epithelial cells. The bacterial crossing through the meningeal capillaries is considered as the more likely scenario, although bacteria inside of meningeal endothelial cells or between them has not been addressed in this study. Another study could indeed demonstrate meningococci localized inside of brain endothelial cells of an infected patient, but again the authors found meningococci also attached to and inside of choroidal endothelial cells [122]. The choroid plexus being a possible entry site is also supported by the findings of high concentrations of meningococci in blood vessels of the choroid plexus and also, even if sporadic, in the choroid plexus epithelium [123]. Interacting with several components of the brain barriers, no final conclusion regarding the exact invasion site can be drawn [122].

A fact that has to mentioned and is part of the discussion in the context of the choroid plexus being a meningococcal entry site into the CSF is that, in consequence of a penetration via the BCSFB, an inflammation of the plexus (so called plexitis) or of the ventricles and their surrounding ependyma (ventriculitis) would be expected. However, this is rarely observed in clinical practice and if so, then rather as an associated secondary complication. Some bacterial induced ventriculitides, however, may be under diagnosed since magnetic resonance tomography (MRT) is not regularly performed in meningitis patients [124].

In conclusion, the role of the choroid plexus as a meningococcal entry side into the CSF cannot be completely ruled out. In a previously established in vitro model of the BCSFB based on human choroidal epithelial cells, meningococci successfully invade and translocate through the epithelial layer, representing well the properties and barrier characteristics of the BCSFB [125-127]. A co-culture model based on human choroidal epithelial and endothelial cells would be an even better representation of the in vivo morphology of the BCSFB. Such a model would enable investigating the described snapshot during disease with meningococci located on and in choroidal endothelial cells and their way via the epithelial cells into the CSF.

As described above and depicted in Figure 1B, the BCSFB is formed by the epithelial cells of the choroid plexus that is located in the ventricular system. Noteworthy, bacteria interacting with the choroid plexus epithelium make contact first with the basolateral side of the epithelial cells after they have crossed the fenestrated choroid plexus endothelium. 
Interactions of N. meningitidis with the choroid plexus epithelium are summarized in Figure 3. The choroid plexus are often attributed to be CNS sensors [13]. Performing their role thoroughly in response to bacterial, including meningococcal, infection, they secret pro-inflammatory cytokines into the CSF, thereby attracting immune cells such as neutrophils, a hallmark of bacterial meningitis [128-130]. Basolateral infection of human choroidal epithelial cells in vitro displays increased secretion of pro-inflammatory cytokines and chemokines including CXCL2, CXCL3, IL8, and IL6. Expression analysis of pattern recognition receptors (PRRs) reveals TLR2/TLR6 complex interactions with lipoprotein components of the bacterial cell wall more likely than TLR2/TLR1- or TLR4-mediated signaling. Neisseria internalization into epithelial cells in vitro also seems rather to involve TLR2/TLR1 than TLR4 signaling [131]. The PorB protein of Neisseria is considered as a TLR2/TLR6 ligand [132]. As shown with B cells from MyD88 and TLR2 knockout mice and cell lines in vitro, meningococcal PorB can directly interact with TLR2, leading to activation of immune cells via the TLR2/TLR1 complex and MyD88 dependent signaling $[133,134]$. In addition, a TLR2-dependent induction of $\mathrm{I} \kappa \mathrm{B} \zeta$ has been described [135], and N. meningitidis capsular polysaccharides induce inflammatory responses via TLR2 and TLR4-MD-2 in cell cultures in vitro [136].

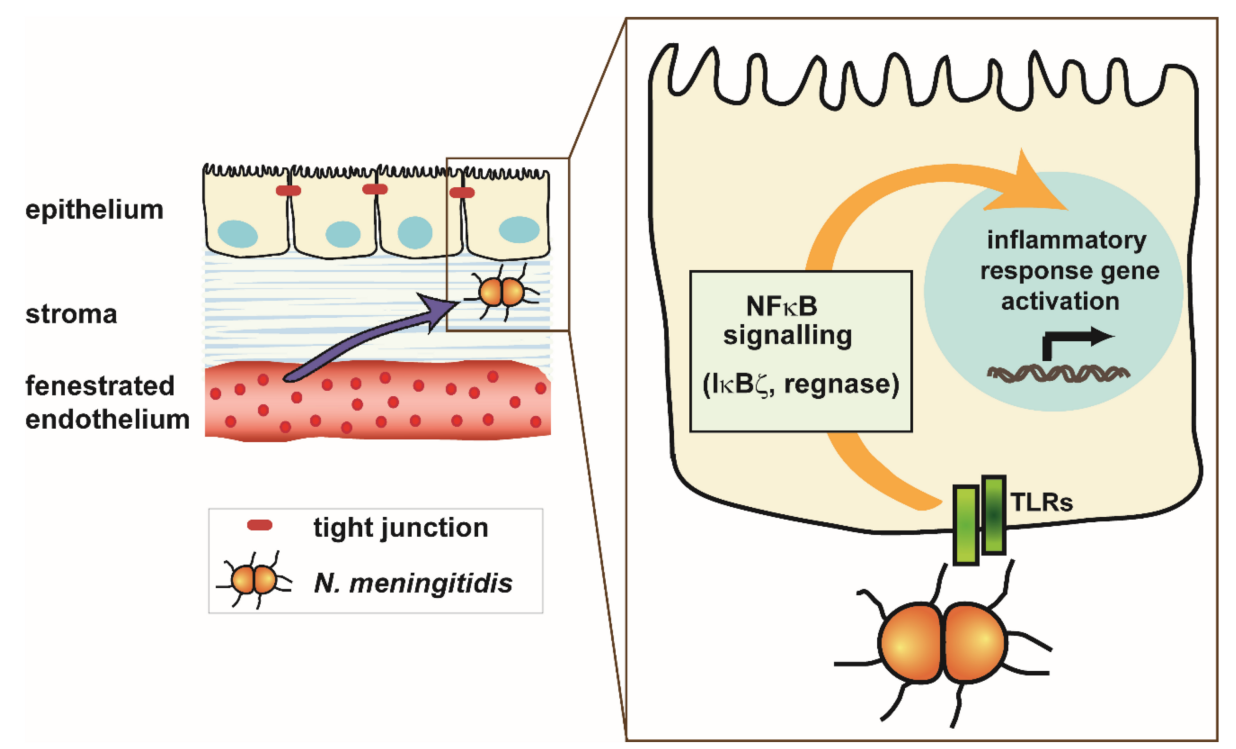

Figure 3. Interaction of Neisseria meningitidis with the choroid plexus epithelium. At the choroid plexus, the endothelial cells forming the capillaries are fenestrated and separated from the epithelium, which is tightly sealed by tight junctions, by a stroma. Meningococci reaching the epithelial cells interact with toll like receptors (TLRs), resulting in an NFKB-mediated activation of a pro-inflammatory immune response. $\mathrm{NF} \kappa \mathrm{B}$ signaling involves the transcription factor $\mathrm{I} \kappa \mathrm{B} \zeta$ as well as the ribonuclease regnase that mediates posttranscriptional regulation of inflammatory immune response genes.

Involvement of intracellular PRRs can also be considered for choroidal epithelial cells. PRR expression in the human plexus is still a secret, since it has never been analyzed. The only expression data of TLR2 and TLR4 are available from choroid plexus and meningeal vessels in mice and rat [137,138]. Receptor interactions in choroid epithelial cells in vitro result in an NFKB-mediated pro-inflammatory immune response involving the transcription factor $\mathrm{I} \kappa \mathrm{B} \zeta$ as well as regnase, a ribonuclease involved in posttranscriptional regulation of the inflammatory immune response $[127,139]$. NFkB-mediated as well as MAPK signaling involved in internalization has also been reported for bronchial epithelial cells [131].

Transmigrated meningococci have been observed in the in vitro model consisting of human choroidal epithelial cells in form of microcolinies at the apical cell side [125]. However, the putative signal transduction pathways in the transmigration process are unknown. Taken together, the choroid 
plexus is actively involved in meningitis pathogenesis, even though its role as a primary entry site may remain to be clarified.

\subsubsection{Neisserial Interactions with the Blood-Cerebrospinal Fluid Barrier at the Meninges}

Bacterial meningitis predominantly represents an inflammation of the meninges, particularly the leptomeninges, composed of the pia mater and the arachnoid mater, with little or no involvement of the dura mater or the underlying brain parenchyma [19]. Thus, one hypothetical entry port into the CSF for meningococci, rather than the BBB, are veins in the SAS with endothelial walls, constituting the first line of barrier at the meningeal barrier, another component of the BCSFB (Figure 1C). The veins in the SAS are surrounded by a thin layer of connective tissue followed by a leptomeningeal lining that have to be penetrated to get access to the CSF-filled SAS [12].

Therefore, one focus of research is the investigation of meningococcal interactions with cells of the leptomeninges. Since the attempts to successfully culture primary human leptomeningeal cells failed [140], and in vivo animal models exhibit significant anatomical differences of the meninges compared to humans [19], two alternative models have previously been established, relying on cryostat sections of fresh human brain and cells cultured from benign tumors of the leptomeninges (meningiomas) [104]. Meningioma cells provide several benefits to cryostat sections and exhibit essential markers of leptomeningeal cells in vivo representing well the meningeal barrier $[104,140]$.

Meningococci preferentially bind to leptomeningeal cells and meningeal blood vessels, but not to cortical brain tissue [104]. Meningococci similarly adhered to meningioma cells; however, no internalization could be observed [104], thus an intercellular crossing involving desmosomes appears more likely [12]. Several potential receptors binding meningococcal ligands can be postulated for leptomeningeal cells [12]. However, several well-known candidates including members of the TLR family, such as TLR2, TLR4, MD-2, or CD14, or LPS-accessory surface proteins HSP70 and HSP90a, chemokine receptor CXCR4, and growth differentiation factor (GDF) 5, seem not to be involved in the signaling upon meningeal meningococcal infection. Recognition of LPS and non-LPS modulins by meningeal cells more likely is dependent on the expression of yet uncharacterized PRRs [141].

Interaction of meningococci with meningioma cells in vitro leads to regulation of host cell genes, including genes for several pro-inflammatory and chemotactic cytokines and chemokines, such as TNF $\alpha$, IL-6, IL-8, MIP-2 $\alpha$, and MCP-1, and genes for apoptosis-related factors including caspase-10, brain-derived neurotropic factor, IEX-1L anti-death protein, IRF-1, osteopontin, and the BB2-bombesin receptor [142]. It was furthermore shown that upon meningococcal infection meningioma cells specifically secrete pro-inflammatory (IL-6), chemotactic (IL-8, MCP-1, and RANTES), and growth factor-related (GM-CSF) cytokines $[19,143]$. Expression levels were affected by the presence of meningococcal surface components, such as Tfp, LPS, capsule, and possible secreted components [19]. A role of secreted proteins from $N$. meningitidis during differential gene expression and immune modulation in meningeal-derived cells was later confirmed. In those experiments, expression of IL-8, IL-6 ICAM-1, and COX-2 was shown [144]. Cytokines were also secreted when meningioma cells were challenged with the closely related organism $N$. lactamica, but levels of IL6 were significantly lower when cells were infected with $N$. lactamica.

Thus, leptomeningeal cells are actively involved in the innate immune response, secreting inflammatory cytokines, thereby contributing to the "inflammatory soup" of host molecules found in the CSF during leptomeningitis pathogenesis [12,19].

\section{Conclusions}

To enter the CNS, N. meningitidis has to cross the barriers between the blood and the brain, which are constituted by the BBB at the brain capillaries and the BCSFB at the choroid plexus and the meninges. At all of those barriers, meningococci undergo interactions with host cell factors, which lead to activation of signal transduction pathways. These pathways can contribute to plasma membrane remodeling during the adhesion and entry of the bacteria into the host cell, as well as to 
the regulation of the inflammatory response. However, further research is required to investigate in detail the interactions and involved signaling mechanisms at the different barriers. The disclosure of differences and commonalities will be very important to develop targeted strategies for treatment during the pathogenesis of meningococcal CNS infections.

Author Contributions: Conceptualization, J.B. and C.S.; writing—original draft preparation, J.B. and C.S.; and writing-review and editing, C.S. and H.S. All authors have read and agreed to the published version of the manuscript.

Funding: This research received no external funding.

Conflicts of Interest: The authors declare no conflict of interest.

\section{Abbreviations}

\begin{tabular}{|c|c|}
\hline AJ & Adherens junction \\
\hline APC & Antigen presenting cell \\
\hline ASM & Acid sphingomyelinase \\
\hline$\beta 2 \mathrm{AR}$ & $\beta 2$-adrenergic receptor \\
\hline BBB & Blood-brain barrier \\
\hline BCSFB & Blood-cerebrospinal fluid barrier \\
\hline CEACAM & Carcinoembryonic antigen-related cell adhesion molecules \\
\hline CNS & Central nervous system \\
\hline CSF & Cerebrospinal fluid \\
\hline $\mathrm{CVO}$ & Circumventricular organ \\
\hline ECM & Extracellular matrix \\
\hline FAK & Focal adhesion kinase \\
\hline GDF & Growth differentiation factor \\
\hline GLUT1 & Glucose transporter 1 \\
\hline HSPG & Heparin sulfate proteoglycan \\
\hline IMD & Invasive meningococcal disease \\
\hline JAM & Junction adhesion molecule \\
\hline LPS & Lipopolysaccharide \\
\hline MAGUK & Membrane-associated guanylate kinase \\
\hline MAPK & Mitogen-activated kinase \\
\hline MARVELD3 & MARVEL domain-containing protein 3 \\
\hline MHC & Major histocompatibility complex \\
\hline MLST & Multi locus sequence typing \\
\hline MMP & Matrix metalloprotease \\
\hline MRT & Magnetic resonance tomography \\
\hline N. meningitidis & Neisseria mengitidis \\
\hline ORF & Open reading frame \\
\hline PC-PLC & Phosphatidylcholine specific phospholipase C \\
\hline pdhC & Pyruvate dehydrogenase subunit \\
\hline PECAM & Platelet endothelial cell adhesion molecule \\
\hline PLVAP & Plasmalemma vesicle-associated protein \\
\hline Pgp & P-glycoprotein \\
\hline PRR & Pattern recognition receptor \\
\hline SAS & Subarachnoidal space \\
\hline SLC & Solute carrier \\
\hline ssm & Single strand mispairing \\
\hline TAMP & Tight junction-associated MARVEL protein \\
\hline TEER & Transepithelial electrical resistance \\
\hline $\mathrm{TJ}$ & Tight junction \\
\hline $\operatorname{Tfp}$ & Type IV pilus \\
\hline TLR & Toll like receptor \\
\hline
\end{tabular}


VE-cadherin vascular endothelial cadherin

VEGF Vascular endothelial growth factor

$\mathrm{ZO}$

Zonula occludens

\section{References}

1. Rouphael, N.G.; Stephens, D.S. Neisseria meningitidis: Biology, microbiology, and epidemiology. Methods Mol. Biol. 2012, 799, 1-20. [CrossRef] [PubMed]

2. Coureuil, M.; Jamet, A.; Bille, E.; Lecuyer, H.; Bourdoulous, S.; Nassif, X. Molecular interactions between Neisseria meningitidis and its human host. Cell. Microbiol. 2019, 21, e13063. [CrossRef] [PubMed]

3. Adriani, K.S.; Brouwer, M.C.; Baas, F.; Zwinderman, A.H.; van der Ende, A.; van de Beek, D. Genetic variation in the $\beta 2$-adrenocepter gene is associated with susceptibility to bacterial meningitis in adults. PLoS ONE 2012, 7, e37618. [CrossRef] [PubMed]

4. Brouwer, M.C.; de Gans, J.; Heckenberg, S.G.; Zwinderman, A.H.; van der Poll, T.; van de Beek, D. Host genetic susceptibility to pneumococcal and meningococcal disease: A systematic review and meta-analysis. Lancet Infect. Dis. 2009, 9, 31-44. [CrossRef]

5. Maiden, M.C.; Bygraves, J.A.; Feil, E.; Morelli, G.; Russell, J.E.; Urwin, R.; Zhang, Q.; Zhou, J.; Zurth, K.; Caugant, D.A.; et al. Multilocus sequence typing: A portable approach to the identification of clones within populations of pathogenic microorganisms. Proc. Natl. Acad. Sci. USA 1998, 95, 3140-3145. [CrossRef]

6. Bille, E.; Meyer, J.; Jamet, A.; Euphrasie, D.; Barnier, J.P.; Brissac, T.; Larsen, A.; Pelissier, P.; Nassif, X. A virulence-associated filamentous bacteriophage of Neisseria meningitidis increases host-cell colonisation. PLoS Pathog. 2017, 13, e1006495. [CrossRef]

7. Bille, E.; Zahar, J.R.; Perrin, A.; Morelle, S.; Kriz, P.; Jolley, K.A.; Maiden, M.C.; Dervin, C.; Nassif, X.; Tinsley, C.R. A chromosomally integrated bacteriophage in invasive meningococci. J. Exp. Med. 2005, 201, 1905-1913. [CrossRef]

8. Caugant, D.A.; Tzanakaki, G.; Kriz, P. Lessons from meningococcal carriage studies. FEMS Microbiol. Rev. 2007, 31, 52-63. [CrossRef]

9. Hill, D.J.; Griffiths, N.J.; Borodina, E.; Virji, M. Cellular and molecular biology of Neisseria meningitidis colonization and invasive disease. Clin. Sci. (London, England: 1979) 2010, 118, 547-564. [CrossRef]

10. Peterson, M.E.; Li, Y.; Bita, A.; Moureau, A.; Nair, H.; Kyaw, M.H.; Meningococcal Surveillance, G.; Abad, R.; Bailey, F.; Garcia, I.F.; et al. Meningococcal serogroups and surveillance: A systematic review and survey. J. Glob. Health 2019, 9, 010409. [CrossRef]

11. Brady, R.C. Meningococcal Infections in Children and Adolescents: Update and Prevention. Adv. Pediatr. 2020, 67, 29-46. [CrossRef] [PubMed]

12. Weller, R.O.; Sharp, M.M.; Christodoulides, M.; Carare, R.O.; Møllgård, K. The meninges as barriers and facilitators for the movement of fluid, cells and pathogens related to the rodent and human CNS. Acta Neuropathol. 2018, 135, 363-385. [CrossRef] [PubMed]

13. Ghersi-Egea, J.F.; Strazielle, N.; Catala, M.; Silva-Vargas, V.; Doetsch, F.; Engelhardt, B. Molecular anatomy and functions of the choroidal blood-cerebrospinal fluid barrier in health and disease. Acta Neuropathol. 2018, 135, 337-361. [CrossRef] [PubMed]

14. Saunders, N.R.; Dziegielewska, K.M.; Mollgard, K.; Habgood, M.D. Physiology and molecular biology of barrier mechanisms in the fetal and neonatal brain. J. Physiol. 2018, 596, 5723-5756. [CrossRef] [PubMed]

15. Erickson, M.A.; Banks, W.A. Neuroimmune Axes of the Blood-Brain Barriers and Blood-Brain Interfaces: Bases for Physiological Regulation, Disease States, and Pharmacological Interventions. Pharmacol. Rev. 2018, 70, 278-314. [CrossRef] [PubMed]

16. Castro Dias, M.; Mapunda, J.A.; Vladymyrov, M.; Engelhardt, B. Structure and Junctional Complexes of Endothelial, Epithelial and Glial Brain Barriers. Int. J. Mol. Sci. 2019, 20, 5372. [CrossRef]

17. Butt, A.M.; Jones, H.C.; Abbott, N.J. Electrical resistance across the blood-brain barrier in anaesthetized rats: A developmental study. J. Physiol. 1990, 429, 47-62. [CrossRef] [PubMed]

18. Join-Lambert, O.; Morand, P.C.; Carbonnelle, E.; Coureuil, M.; Bille, E.; Bourdoulous, S.; Nassif, X. Mechanisms of meningeal invasion by a bacterial extracellular pathogen, the example of Neisseria meningitidis. Prog. Neurobiol. 2010, 130-139. [CrossRef] 
19. Christodoulides, M.; Makepeace, B.L.; Partridge, K.A.; Kaur, D.; Fowler, M.I.; Weller, R.O.; Heckels, J.E. Interaction of Neisseria meningitidis with human meningeal cells induces the secretion of a distinct group of chemotactic, proinflammatory, and growth-factor cytokines. Infect. Immun. 2002, 70, 4035-4044. [CrossRef]

20. Rua, R.; McGavern, D.B. Advances in Meningeal Immunity. Trends Mol. Med. 2018, 24, 542-559. [CrossRef]

21. Chamot-Rooke, J.; Mikaty, G.; Malosse, C.; Soyer, M.; Dumont, A.; Gault, J.; Imhaus, A.F.; Martin, P.; Trellet, M.; Clary, G.; et al. Posttranslational modification of pili upon cell contact triggers N. meningitidis dissemination. Science 2011, 331, 778-782. [CrossRef] [PubMed]

22. Pujol, C.; Eugene, E.; de Saint Martin, L.; Nassif, X. Interaction of Neisseria meningitidis with a polarized monolayer of epithelial cells. Infect. Immun. 1997, 65, 4836-4842. [CrossRef] [PubMed]

23. Nassif, X.; Beretti, J.L.; Lowy, J.; Stenberg, P.; O'Gaora, P.; Pfeifer, J.; Normark, S.; So, M. Roles of pilin and PilC in adhesion of Neisseria meningitidis to human epithelial and endothelial cells. Proc. Natl. Acad. Sci. USA 1994, 91, 3769-3773. [CrossRef] [PubMed]

24. Exley, R.M.; Sim, R.; Goodwin, L.; Winterbotham, M.; Schneider, M.C.; Read, R.C.; Tang, C.M. Identification of meningococcal genes necessary for colonization of human upper airway tissue. Infect. Immun. 2009, 77, 45-51. [CrossRef] [PubMed]

25. Stephens, D.S.; McGee, Z.A. Attachment of Neisseria meningitidis to human mucosal surfaces: Influence of pili and type of receptor cell. J. Infect. Dis. 1981, 143, 525-532. [CrossRef] [PubMed]

26. Merz, A.J.; Rifenbery, D.B.; Arvidson, C.G.; So, M. Traversal of a polarized epithelium by pathogenic Neisseriae: Facilitation by type IV pili and maintenance of epithelial barrier function. Mol. Med. 1996, 2, 745-754. [CrossRef]

27. Kallstrom, H.; Liszewski, M.K.; Atkinson, J.P.; Jonsson, A.B. Membrane cofactor protein (MCP or CD46) is a cellular pilus receptor for pathogenic Neisseria. Mol. Microbiol. 1997, 25, 639-647. [CrossRef]

28. Johansson, L.; Rytkonen, A.; Bergman, P.; Albiger, B.; Kallstrom, H.; Hokfelt, T.; Agerberth, B.; Cattaneo, R.; Jonsson, A.B. CD46 in meningococcal disease. Science 2003, 301, 373-375. [CrossRef]

29. Teuchert, M.; Maisner, A.; Herrler, G. Importance of the carboxyl-terminal FTSL motif of membrane cofactor protein for basolateral sorting and endocytosis. Positive and negative modulation by signals inside and outside the cytoplasmic tail. J. Biol. Chem. 1999, 274, 19979-19984. [CrossRef]

30. Maisner, A.; Liszewski, M.K.; Atkinson, J.P.; Schwartz-Albiez, R.; Herrler, G. Two different cytoplasmic tails direct isoforms of the membrane cofactor protein (CD46) to the basolateral surface of Madin-Darby canine kidney cells. J. Biol. Chem. 1996, 271, 18853-18858. [CrossRef]

31. Gill, D.B.; Atkinson, J.P. CD46 in Neisseria pathogenesis. Trends Mol. Med. 2004, 10, 459-465. [CrossRef] [PubMed]

32. Kirchner, M.; Heuer, D.; Meyer, T.F. CD46-independent binding of neisserial type IV pili and the major pilus adhesin, PilC, to human epithelial cells. Infect. Immun. 2005, 73, 3072-3082. [CrossRef] [PubMed]

33. Kirchner, M.; Meyer, T.F. The PilC adhesin of the Neisseria type IV pilus-binding specificities and new insights into the nature of the host cell receptor. Mol. Microbiol. 2005, 56, 945-957. [CrossRef] [PubMed]

34. Sutherland, T.C.; Quattroni, P.; Exley, R.M.; Tang, C.M. Transcellular passage of Neisseria meningitidis across a polarized respiratory epithelium. Infect. Immun. 2010, 78, 3832-3847. [CrossRef]

35. Merz, A.J.; Enns, C.A.; So, M. Type IV pili of pathogenic Neisseriae elicit cortical plaque formation in epithelial cells. Mol. Microbiol. 1999, 32, 1316-1332. [CrossRef]

36. Merz, A.J.; So, M. Attachment of piliated, Opa- and Opc- gonococci and meningococci to epithelial cells elicits cortical actin rearrangements and clustering of tyrosine-phosphorylated proteins. Infect. Immun. 1997, 65, 4341-4349. [CrossRef]

37. Stephens, D.S.; Hoffman, L.H.; McGee, Z.A. Interaction of Neisseria meningitidis with human nasopharyngeal mucosa: Attachment and entry into columnar epithelial cells. J. Infect. Dis. 1983, 148, 369-376. [CrossRef]

38. Deghmane, A.E.; Giorgini, D.; Larribe, M.; Alonso, J.M.; Taha, M.K. Down-regulation of pili and capsule of Neisseria meningitidis upon contact with epithelial cells is mediated by CrgA regulatory protein. Mol. Microbiol. 2002, 43, 1555-1564. [CrossRef]

39. Spinosa, M.R.; Progida, C.; Talà, A.; Cogli, L.; Alifano, P.; Bucci, C. The Neisseria meningitidis capsule is important for intracellular survival in human cells. Infect. Immun. 2007, 75, 3594-3603. [CrossRef]

40. Sjölinder, H.; Jonsson, A.B. Olfactory nerve-a novel invasion route of Neisseria meningitidis to reach the meninges. PLoS ONE 2010, 5, e14034. [CrossRef] 
41. Khairalla, A.S.; Omer, S.A.; Mahdavi, J.; Aslam, A.; Dufailu, O.A.; Self, T.; Jonsson, A.B.; Geörg, M.; Sjölinder, H.; Royer, P.J.; et al. Nuclear trafficking, histone cleavage and induction of apoptosis by the meningococcal App and MspA autotransporters. Cell. Microbiol. 2015, 17, 1008-1020. [CrossRef] [PubMed]

42. Sadarangani, M.; Pollard, A.J.; Gray-Owen, S.D. Opa proteins and CEACAMs: Pathways of immune engagement for pathogenic Neisseria. FEMS Microbiol. Rev. 2011, 35, 498-514. [CrossRef] [PubMed]

43. Johswich, K.O.; McCaw, S.E.; Islam, E.; Sintsova, A.; Gu, A.; Shively, J.E.; Gray-Owen, S.D. In vivo adaptation and persistence of Neisseria meningitidis within the nasopharyngeal mucosa. PLoS Pathog. 2013, 9, e1003509. [CrossRef] [PubMed]

44. Slevogt, H.; Zabel, S.; Opitz, B.; Hocke, A.; Eitel, J.; N’Guessan, P.D.; Lucka, L.; Riesbeck, K.; Zimmermann, W.; Zweigner, J.; et al. CEACAM1 inhibits Toll-like receptor 2-triggered antibacterial responses of human pulmonary epithelial cells. Nat. Immunol. 2008, 9, 1270-1278. [CrossRef] [PubMed]

45. De Vries, F.P.; Cole, R.; Dankert, J.; Frosch, M.; van Putten, J.P. Neisseria meningitidis producing the Opc adhesin binds epithelial cell proteoglycan receptors. Mol. Microbiol. 1998, 27, 1203-1212. [CrossRef] [PubMed]

46. Virji, M.; Makepeace, K.; Ferguson, D.J.; Achtman, M.; Moxon, E.R. Meningococcal Opa and Opc proteins: Their role in colonization and invasion of human epithelial and endothelial cells. Mol. Microbiol. 1993, 10, 499-510. [CrossRef]

47. Virji, M.; Makepeace, K.; Ferguson, D.J.; Achtman, M.; Sarkari, J.; Moxon, E.R. Expression of the Opc protein correlates with invasion of epithelial and endothelial cells by Neisseria meningitidis. Mol. Microbiol. 1992, 6, 2785-2795. [CrossRef]

48. Müller, M.G.; Moe, N.E.; Richards, P.Q.; Moe, G.R. Resistance of Neisseria meningitidis to human serum depends on $\mathrm{T}$ and B cell stimulating protein B. Infect. Immun. 2015, 83, 1257-1264. [CrossRef]

49. Gómez, J.A.; Criado, M.T.; Ferreirós, C.M. Cooperation between the components of the meningococcal transferrin receptor, $\mathrm{TbpA}$ and $\mathrm{TbpB}$, in the uptake of transferrin iron by the 37-kDa ferric-binding protein (FbpA). Res. Microbiol. 1998, 149, 381-387. [CrossRef]

50. Pettersson, A.; Klarenbeek, V.; van Deurzen, J.; Poolman, J.T.; Tommassen, J. Molecular characterization of the structural gene for the lactoferrin receptor of the meningococcal strain H44/76. Microb. Pathog. 1994, 17, 395-408. [CrossRef]

51. Schryvers, A.B.; Morris, L.J. Identification and characterization of the human lactoferrin-binding protein from Neisseria meningitidis. Infect. Immun. 1988, 56, 1144-1149. [CrossRef]

52. Lewis, L.A.; Dyer, D.W. Identification of an iron-regulated outer membrane protein of Neisseria meningitidis involved in the utilization of hemoglobin complexed to haptoglobin. J. Bacteriol. 1995, 177, 1299-1306. [CrossRef] [PubMed]

53. Stojiljkovic, I.; Hwa, V.; de Saint Martin, L.; O’Gaora, P.; Nassif, X.; Heffron, F.; So, M. The Neisseria meningitidis haemoglobin receptor: Its role in iron utilization and virulence. Mol. Microbiol. 1995, 15, 531-541. [CrossRef] [PubMed]

54. Serruto, D.; Spadafina, T.; Ciucchi, L.; Lewis, L.A.; Ram, S.; Tontini, M.; Santini, L.; Biolchi, A.; Seib, K.L.; Giuliani, M.M.; et al. Neisseria meningitidis GNA2132, a heparin-binding protein that induces protective immunity in humans. Proc. Natl. Acad. Sci. USA 2010, 107, 3770-3775. [CrossRef] [PubMed]

55. Plaut, A.G.; Gilbert, J.V.; Artenstein, M.S.; Capra, J.D. Neisseria gonorrhoeae and neisseria meningitidis: Extracellular enzyme cleaves human immunoglobulin A. Science 1975, 190, 1103-1105. [CrossRef]

56. Jarva, H.; Ram, S.; Vogel, U.; Blom, A.M.; Meri, S. Binding of the complement inhibitor C4bp to serogroup B Neisseria meningitidis. J. Immunol. (Baltimore, Md. 1950) 2005, 174, 6299-6307. [CrossRef]

57. Giuntini, S.; Pajon, R.; Ram, S.; Granoff, D.M. Binding of complement factor H to PorB3 and NspA enhances resistance of Neisseria meningitidis to anti-factor $\mathrm{H}$ binding protein bactericidal activity. Infect. Immun. 2015, 83, 1536-1545. [CrossRef]

58. Seib, K.L.; Scarselli, M.; Comanducci, M.; Toneatto, D.; Masignani, V. Neisseria meningitidis factor H-binding protein fHbp: A key virulence factor and vaccine antigen. Expert Rev. Vaccines 2015, 14, 841-859. [CrossRef]

59. Mackinnon, F.G.; Borrow, R.; Gorringe, A.R.; Fox, A.J.; Jones, D.M.; Robinson, A. Demonstration of lipooligosaccharide immunotype and capsule as virulence factors for Neisseria meningitidis using an infant mouse intranasal infection model. Microb. Pathog. 1993, 15, 359-366. [CrossRef] 
60. Geoffroy, M.C.; Floquet, S.; Métais, A.; Nassif, X.; Pelicic, V. Large-scale analysis of the meningococcus genome by gene disruption: Resistance to complement-mediated lysis. Genome Res. 2003, 13, 391-398. [CrossRef]

61. Beddek, A.J.; Li, M.S.; Kroll, J.S.; Jordan, T.W.; Martin, D.R. Evidence for capsule switching between carried and disease-causing Neisseria meningitidis strains. Infect. Immun. 2009, 77, 2989-2994. [CrossRef] [PubMed]

62. Swartley, J.S.; Marfin, A.A.; Edupuganti, S.; Liu, L.J.; Cieslak, P.; Perkins, B.; Wenger, J.D.; Stephens, D.S. Capsule switching of Neisseria meningitidis. Proc. Natl. Acad. Sci. USA 1997, 94, 271-276. [CrossRef] [PubMed]

63. Tsang, R.S.; Law, D.K.; Tyler, S.D.; Stephens, G.S.; Bigham, M.; Zollinger, W.D. Potential capsule switching from serogroup $Y$ to $B$ : The characterization of three such Neisseria meningitidis isolates causing invasive meningococcal disease in Canada. Can. J. Infect. Dis. Med. Microbiol. 2005, 16, 171-174. [CrossRef]

64. Tettelin, H.; Saunders, N.J.; Heidelberg, J.; Jeffries, A.C.; Nelson, K.E.; Eisen, J.A.; Ketchum, K.A.; Hood, D.W.; Peden, J.F.; Dodson, R.J.; et al. Complete genome sequence of Neisseria meningitidis serogroup B strain MC58. Science 2000, 287, 1809-1815. [CrossRef] [PubMed]

65. Parkhill, J.; Achtman, M.; James, K.D.; Bentley, S.D.; Churcher, C.; Klee, S.R.; Morelli, G.; Basham, D.; Brown, D.; Chillingworth, T.; et al. Complete DNA sequence of a serogroup A strain of Neisseria meningitidis Z2491. Nature 2000, 404, 502-506. [CrossRef] [PubMed]

66. Haas, R.; Meyer, T.F. The repertoire of silent pilus genes in Neisseria gonorrhoeae: Evidence for gene conversion. Cell 1986, 44, 107-115. [CrossRef]

67. Segal, E.; Hagblom, P.; Seifert, H.S.; So, M. Antigenic variation of gonococcal pilus involves assembly of separated silent gene segments. Proc. Natl. Acad. Sci. USA 1986, 83, 2177-2181. [CrossRef]

68. Sarkari, J.; Pandit, N.; Moxon, E.R.; Achtman, M. Variable expression of the Opc outer membrane protein in Neisseria meningitidis is caused by size variation of a promoter containing poly-cytidine. Mol. Microbiol. 1994, 13, 207-217. [CrossRef]

69. Achtman, M. Epidemic spread and antigenic variability of Neisseria meningitidis. Trends Microbiol. 1995, 3, 186-192. [CrossRef]

70. Hammerschmidt, S.; Müller, A.; Sillmann, H.; Mühlenhoff, M.; Borrow, R.; Fox, A.; van Putten, J.; Zollinger, W.D.; Gerardy-Schahn, R.; Frosch, M. Capsule phase variation in Neisseria meningitidis serogroup $B$ by slipped-strand mispairing in the polysialyltransferase gene (siaD): Correlation with bacterial invasion and the outbreak of meningococcal disease. Mol. Microbiol. 1996, 20, 1211-1220. [CrossRef]

71. Jennings, M.P.; Srikhanta, Y.N.; Moxon, E.R.; Kramer, M.; Poolman, J.T.; Kuipers, B.; van der Ley, P. The genetic basis of the phase variation repertoire of lipopolysaccharide immunotypes in Neisseria meningitidis. Microbiology 1999, 145 Pt 11, 3013-3021. [CrossRef]

72. Stern, A.; Brown, M.; Nickel, P.; Meyer, T.F. Opacity genes in Neisseria gonorrhoeae: Control of phase and antigenic variation. Cell 1986, 47,61-71. [CrossRef]

73. Frosch, M.; Vogel, U. Structure and Genetics of the Meningococcal Capsule. In Handbook of Meningococcal Disease; Frosch, M., Maiden, M.C.J., Eds.; Wiley-VCH: Weinheim, Germany, 2006; pp. 145-162.

74. Kahler, C.M.; Stephens, D.S. Genetic basis for biosynthesis, structure, and function of meningococcal lipooligosaccharide (endotoxin). Crit. Rev. Microbiol. 1998, 24, 281-334. [CrossRef]

75. Tsai, C.M. Molecular mimicry of host structures by lipooligosaccharides of Neisseria meningitidis: Characterization of sialylated and nonsialylated lacto-N-neotetraose (Galbeta1-4GlcNAcbeta1-3Galbeta1-4Glc) structures in lipooligosaccharides using monoclonal antibodies and specific lectins. Adv. Exp. Med. Biol. 2001, 491, 525-542. [CrossRef]

76. Lécuyer, H.; Nassif, X.; Coureuil, M. Two strikingly different signaling pathways are induced by meningococcal type IV pili on endothelial and epithelial cells. Infect. Immun. 2012, 80, 175-186. [CrossRef]

77. Bernard, S.C.; Simpson, N.; Join-Lambert, O.; Federici, C.; Laran-Chich, M.P.; Maïssa, N.; Bouzinba-Ségard, H.; Morand, P.C.; Chretien, F.; Taouji, S.; et al. Pathogenic Neisseria meningitidis utilizes CD147 for vascular colonization. Nat. Med. 2014, 20, 725-731. [CrossRef]

78. Join-Lambert, O.; Lecuyer, H.; Miller, F.; Lelievre, L.; Jamet, A.; Furio, L.; Schmitt, A.; Pelissier, P.; Fraitag, S.; Coureuil, M.; et al. Meningococcal interaction to microvasculature triggers the tissular lesions of purpura fulminans. J. Infect. Dis. 2013, 208, 1590-1597. [CrossRef] 
79. Melican, K.; Michea Veloso, P.; Martin, T.; Bruneval, P.; Duménil, G. Adhesion of Neisseria meningitidis to dermal vessels leads to local vascular damage and purpura in a humanized mouse model. PLoS Pathog. 2013, 9, e1003139. [CrossRef]

80. Coureuil, M.; Lécuyer, H.; Bourdoulous, S.; Nassif, X. A journey into the brain: Insight into how bacterial pathogens cross blood-brain barriers. Microbiology 2017, 15. [CrossRef]

81. Kim, B.J.; Schubert-Unkmeir, A. In Vitro Models for Studying the Interaction of Neisseria meningitidis with Human Brain Endothelial Cells. In Neisseria Meningitidis; Humana Press: New York, NY, USA, 2019; Volume 1969, pp. 135-148. [CrossRef]

82. Melican, K.; Aubey, F.; Duménil, G. Humanized mouse model to study bacterial infections targeting the microvasculature. J. Vis. Exp. JoVE 2014, e51134. [CrossRef]

83. Orihuela, C.J.; Mahdavi, J.; Thornton, J.; Mann, B.; Wooldridge, K.G.; Abouseada, N.; Oldfield, N.J.; Self, T.; Ala'Aldeen, D.A.; Tuomanen, E.I. Laminin receptor initiates bacterial contact with the blood brain barrier in experimental meningitis models. J. Clin. Investig. 2009, 119, 1638-1646. [CrossRef]

84. Jen, F.E.; Warren, M.J.; Schulz, B.L.; Power, P.M.; Swords, W.E.; Weiser, J.N.; Apicella, M.A.; Edwards, J.L.; Jennings, M.P. Dual pili post-translational modifications synergize to mediate meningococcal adherence to platelet activating factor receptor on human airway cells. PLoS Pathog. 2013, 9, e1003377. [CrossRef]

85. Martins Gomes, S.F.; Westermann, A.J.; Sauerwein, T.; Hertlein, T.; Forstner, K.U.; Ohlsen, K.; Metzger, M.; Shusta, E.V.; Kim, B.J.; Appelt-Menzel, A.; et al. Induced Pluripotent Stem Cell-Derived Brain Endothelial Cells as a Cellular Model to Study Neisseria meningitidis Infection. Front. Microbiol. 2019, 10, 1181. [CrossRef]

86. Maïssa, N.; Covarelli, V.; Janel, S.; Durel, B.; Simpson, N.; Bernard, S.C.; Pardo-Lopez, L.; Bouzinba-Ségard, H.; Faure, C.; Scott, M.G.H.; et al. Strength of Neisseria meningitidis binding to endothelial cells requires highly-ordered CD147/ $\beta(2)$-adrenoceptor clusters assembled by alpha-actinin-4. Nat. Commun. 2017, 8, 15764. [CrossRef]

87. Eugene, E.; Hoffmann, I.; Pujol, C.; Couraud, P.O.; Bourdoulous, S.; Nassif, X. Microvilli-like structures are associated with the internalization of virulent capsulated Neisseria meningitidis into vascular endothelial cells. J. Cell Sci. 2002, 115, 1231-1241.

88. Coureuil, M.; Lécuyer, H.; Scott, M.G.; Boularan, C.; Enslen, H.; Soyer, M.; Mikaty, G.; Bourdoulous, S.; Nassif, X.; Marullo, S. Meningococcus Hijacks a $\beta 2$-adrenoceptor/ $\beta$-Arrestin pathway to cross brain microvasculature endothelium. Cell 2010, 143, 1149-1160. [CrossRef]

89. Luttrell, L.M.; Ferguson, S.S.; Daaka, Y.; Miller, W.E.; Maudsley, S.; Della Rocca, G.J.; Lin, F.; Kawakatsu, H.; Owada, K.; Luttrell, D.K.; et al. Beta-arrestin-dependent formation of beta2 adrenergic receptor-Src protein kinase complexes. Science 1999, 283, 655-661. [CrossRef]

90. Mikaty, G.; Soyer, M.; Mairey, E.; Henry, N.; Dyer, D.; Forest, K.T.; Morand, P.; Guadagnini, S.; Prevost, M.C.; Nassif, X.; et al. Extracellular bacterial pathogen induces host cell surface reorganization to resist shear stress. PLoS Pathog. 2009, 5, e1000314. [CrossRef]

91. Doulet, N.; Donnadieu, E.; Laran-Chich, M.P.; Niedergang, F.; Nassif, X.; Couraud, P.O.; Bourdoulous, S. Neisseria meningitidis infection of human endothelial cells interferes with leukocyte transmigration by preventing the formation of endothelial docking structures. J. Cell Biol. 2006, 173, 627-637. [CrossRef]

92. Slanina, H.; Mündlein, S.; Hebling, S.; Schubert-Unkmeir, A. Role of epidermal growth factor receptor signaling in the interaction of Neisseria meningitidis with endothelial cells. Infect. Immun. 2014, 82, 1243-1255. [CrossRef]

93. Hoffmann, I.; Eugène, E.; Nassif, X.; Couraud, P.O.; Bourdoulous, S. Activation of ErbB2 receptor tyrosine kinase supports invasion of endothelial cells by Neisseria meningitidis. J. Cell Biol. 2001, 155, 133-143. [CrossRef]

94. DeFea, K.A.; Zalevsky, J.; Thoma, M.S.; Déry, O.; Mullins, R.D.; Bunnett, N.W. beta-arrestin-dependent endocytosis of proteinase-activated receptor 2 is required for intracellular targeting of activated ERK1/2. J. Cell Biol. 2000, 148, 1267-1281. [CrossRef]

95. Luttrell, L.M.; Roudabush, F.L.; Choy, E.W.; Miller, W.E.; Field, M.E.; Pierce, K.L.; Lefkowitz, R.J. Activation and targeting of extracellular signal-regulated kinases by beta-arrestin scaffolds. Proc. Natl. Acad. Sci. USA 2001, 98, 2449-2454. [CrossRef] 
96. Sokolova, O.; Heppel, N.; Jägerhuber, R.; Kim, K.S.; Frosch, M.; Eigenthaler, M.; Schubert-Unkmeir, A. Interaction of Neisseria meningitidis with human brain microvascular endothelial cells: Role of MAPand tyrosine kinases in invasion and inflammatory cytokine release. Cell. Microbiol. 2004, 6, 1153-1166. [CrossRef]

97. Lambotin, M.; Hoffmann, I.; Laran-Chich, M.P.; Nassif, X.; Couraud, P.O.; Bourdoulous, S. Invasion of endothelial cells by Neisseria meningitidis requires cortactin recruitment by a phosphoinositide-3-kinase/Rac1 signalling pathway triggered by the lipo-oligosaccharide. J. Cell Sci. 2005, 118, 3805-3816. [CrossRef]

98. Nikulin, J.; Panzner, U.; Frosch, M.; Schubert-Unkmeir, A. Intracellular survival and replication of Neisseria meningitidis in human brain microvascular endothelial cells. Int. J. Med Microbiol. 2006, 296, 553-558. [CrossRef]

99. Coureuil, M.; Mikaty, G.; Miller, F.; Lecuyer, H.; Bernard, C.; Bourdoulous, S.; Dumenil, G.; Mege, R.M.; Weksler, B.B.; Romero, I.A.; et al. Meningococcal type IV pili recruit the polarity complex to cross the brain endothelium. Science 2009, 325, 83-87. [CrossRef]

100. Schubert-Unkmeir, A.; Konrad, C.; Slanina, H.; Czapek, F.; Hebling, S.; Frosch, M. Neisseria meningitidis induces brain microvascular endothelial cell detachment from the matrix and cleavage of occludin: A role for MMP-8. PLoS Pathog. 2010, 6, e1000874. [CrossRef]

101. Schubert-Unkmeir, A.; Sokolova, O.; Panzner, U.; Eigenthaler, M.; Frosch, M. Gene expression pattern in human brain endothelial cells in response to Neisseria meningitidis. Infect. Immun. 2007, 75, 899-914. [CrossRef]

102. Mairey, E.; Genovesio, A.; Donnadieu, E.; Bernard, C.; Jaubert, F.; Pinard, E.; Seylaz, J.; Olivo-Marin, J.C.; Nassif, X.; Dumenil, G. Cerebral microcirculation shear stress levels determine Neisseria meningitidis attachment sites along the blood-brain barrier. J. Exp. Med. 2006, 203, 1939-1950. [CrossRef]

103. Ká, E.; Jiménez-Munguía, I.; Majerová, P.; Tkáčová, Z.; Bhide, K.; Mertinková, P.; Pulzová, L.; Kováč, A.; Bhide, M. Deciphering the Interactome of Neisseria meningitidis With Human Brain Microvascular Endothelial Cells. Front. Microbiol. 2018, 9, 2294. [CrossRef]

104. Hardy, S.J.; Christodoulides, M.; Weller, R.O.; Heckels, J.E. Interactions of Neisseria meningitidis with cells of the human meninges. Mol. Microbiol. 2000, 36, 817-829. [CrossRef]

105. Unkmeir, A.; Latsch, K.; Dietrich, G.; Wintermeyer, E.; Schinke, B.; Schwender, S.; Kim, K.S.; Eigenthaler, M.; Frosch, M. Fibronectin mediates Opc-dependent internalization of Neisseria meningitidis in human brain microvascular endothelial cells. Mol. Microbiol. 2002, 46, 933-946. [CrossRef]

106. Bradley, C.J.; Griffiths, N.J.; Rowe, H.A.; Heyderman, R.S.; Virji, M. Critical determinants of the interactions of capsule-expressing Neisseria meningitidis with host cells: The role of receptor density in increased cellular targeting via the outer membrane Opa proteins. Cell. Microbiol. 2005, 7, 1490-1503. [CrossRef]

107. Schubert-Unkmeir, A. Molecular mechanisms involved in the interaction of Neisseria meningitidis with cells of the human blood-cerebrospinal fluid barrier. Pathog. Dis. 2017, 75. [CrossRef]

108. Virji, M.; Makepeace, K.; Ferguson, D.J.; Watt, S.M. Carcinoembryonic antigens (CD66) on epithelial cells and neutrophils are receptors for Opa proteins of pathogenic neisseriae. Mol. Microbiol. 1996, 22, 941-950. [CrossRef]

109. Virji, M.; Makepeace, K.; Moxon, E.R. Distinct mechanisms of interactions of Opc-expressing meningococci at apical and basolateral surfaces of human endothelial cells; the role of integrins in apical interactions. Mol. Microbiol. 1994, 14, 173-184. [CrossRef]

110. Sa, E.C.C.; Griffiths, N.J.; Virji, M. Neisseria meningitidis Opc invasin binds to the sulphated tyrosines of activated vitronectin to attach to and invade human brain endothelial cells. PLoS Pathog. 2010, 6, e1000911. [CrossRef]

111. Giancotti, F.G.; Ruoslahti, E. Integrin signaling. Science 1999, 285, 1028-1032. [CrossRef]

112. Slanina, H.; König, A.; Hebling, S.; Hauck, C.R.; Frosch, M.; Schubert-Unkmeir, A. Entry of Neisseria meningitidis into mammalian cells requires the Src family protein tyrosine kinases. Infect. Immun. 2010, 78, 1905-1914. [CrossRef]

113. Slanina, H.; Hebling, S.; Hauck, C.R.; Schubert-Unkmeir, A. Cell invasion by Neisseria meningitidis requires a functional interplay between the focal adhesion kinase, Src and cortactin. PLoS ONE 2012, 7, e39613. [CrossRef] [PubMed]

114. Sa, E.C.C.; Griffiths, N.J.; Murillo, I.; Virji, M. Neisseria meningitidis Opc invasin binds to the cytoskeletal protein alpha-actinin. Cell. Microbiol. 2009, 11, 389-405. [CrossRef] [PubMed] 
115. Seiler, A.; Reinhardt, R.; Sarkari, J.; Caugant, D.A.; Achtman, M. Allelic polymorphism and site-specific recombination in the opc locus of Neisseria meningitidis. Mol. Microbiol. 1996, 19, 841-856. [CrossRef]

116. Kriz, P.; Vlckova, J.; Bobak, M. Targeted vaccination with meningococcal polysaccharide vaccine in one district of the Czech Republic. Epidemiol. Infect. 1995, 115, 411-418. [CrossRef] [PubMed]

117. Whalen, C.M.; Hockin, J.C.; Ryan, A.; Ashton, F. The changing epidemiology of invasive meningococcal disease in Canada, 1985 through 1992. Emergence of a virulent clone of Neisseria meningitidis. JAMA 1995, 273, 390-394. [CrossRef]

118. Oosthuysen, W.F.; Mueller, T.; Dittrich, M.T.; Schubert-Unkmeir, A. Neisseria meningitidis causes cell cycle arrest of human brain microvascular endothelial cells at $\mathrm{S}$ phase via 21 and cyclin G2. Cell. Microbiol. 2016, 18, 46-65. [CrossRef]

119. Von Papen, M.; Oosthuysen, W.F.; Becam, J.; Claus, H.; Schubert-Unkmeir, A. Disease and Carrier Isolates of Neisseria meningitidis Cause G1 Cell Cycle Arrest in Human Epithelial Cells. Infect. Immun. 2016, 84, 2758-2770. [CrossRef]

120. Simonis, A.; Hebling, S.; Gulbins, E.; Schneider-Schaulies, S.; Schubert-Unkmeir, A. Differential activation of acid sphingomyelinase and ceramide release determines invasiveness of Neisseria meningitidis into brain endothelial cells. PLoS Pathog. 2014, 10, e1004160. [CrossRef]

121. Pron, B.; Taha, M.K.; Rambaud, C.; Fournet, J.C.; Pattey, N.; Monnet, J.P.; Musilek, M.; Beretti, J.L.; Nassif, X. Interaction of Neisseria maningitidis with the components of the blood-brain barrier correlates with an increased expression of PilC. J. Infect. Dis. 1997, 176, 1285-1292. [CrossRef]

122. Nassif, X.; Bourdoulous, S.; Eugène, E.; Couraud, P.O. How do extracellular pathogens cross the blood-brain barrier? Trends Microbiol. 2002, 10, 227-232. [CrossRef]

123. Guarner, J.; Greer, P.W.; Whitney, A.; Shieh, W.J.; Fischer, M.; White, E.H.; Carlone, G.M.; Stephens, D.S.; Popovic, T.; Zaki, S.R. Pathogenesis and diagnosis of human meningococcal disease using immunohistochemical and PCR assays. Am. J. Clin. Pathol. 2004, 122, 754-764. [CrossRef] [PubMed]

124. Woehrl, B.; Linn, J.; Lummel, N.; Pfefferkorn, T.; Koedel, U.; Pfister, H.W.; Klein, M. Pneumococcal meningitis-associated pyogenic ventriculitis. J. Infect. 2015, 70, 311-314. [CrossRef]

125. Schwerk, C.; Papandreou, T.; Schuhmann, D.; Nickol, L.; Borkowski, J.; Steinmann, U.; Quednau, N.; Stump, C.; Weiss, C.; Berger, J.; et al. Polar Invasion and Translocation of Neisseria meningitidis and Streptococcus suis in a Novel Human Model of the Blood-Cerebrospinal Fluid Barrier. PLoS ONE 2012, 7 , e30069. [CrossRef] [PubMed]

126. Dinner, S.; Borkowski, J.; Stump-Guthier, C.; Ishikawa, H.; Tenenbaum, T.; Schroten, H.; Schwerk, C. A Choroid Plexus Epithelial Cell-based Model of the Human Blood-Cerebrospinal Fluid Barrier to Study Bacterial Infection from the Basolateral Side. J. Vis. Exp. Jove 2016. [CrossRef] [PubMed]

127. Borkowski, J.; Li, L.; Steinmann, U.; Quednau, N.; Stump-Guthier, C.; Weiss, C.; Findeisen, P.; Gretz, N.; Ishikawa, H.; Tenenbaum, T.; et al. Neisseria meningitidis elicits a pro-inflammatory response involving IKB $\zeta$ in a human blood-cerebrospinal fluid barrier model. J. Neuroinflamm. 2014, 11, 163. [CrossRef] [PubMed]

128. Neal, J.W.; Gasque, P. How does the brain limit the severity of inflammation and tissue injury during bacterial meningitis? J. Neuropathol. Exp. Neurol. 2013, 72, 370-385. [CrossRef]

129. Steinmann, U.; Borkowski, J.; Wolburg, H.; Schröppel, B.; Findeisen, P.; Weiss, C.; Ishikawa, H.; Schwerk, C.; Schroten, H.; Tenenbaum, T. Transmigration of polymorphnuclear neutrophils and monocytes through the human blood-cerebrospinal fluid barrier after bacterial infection in vitro. J. Neuroinflamm. 2013, 10, 31. [CrossRef]

130. Schwerk, C.; Adam, R.; Borkowski, J.; Schneider, H.; Klenk, M.; Zink, S.; Quednau, N.; Schmidt, N.; Stump, C.; Sagar, A.; et al. In vitro transcriptome analysis of porcine choroid plexus epithelial cells in response to Streptococcus suis: Release of pro-inflammatory cytokines and chemokines. Microbes Infect. Inst. Pasteur 2011, 13, 953-962. [CrossRef]

131. Toussi, D.N.; Wetzler, L.M.; Liu, X.; Massari, P. Neisseriae internalization by epithelial cells is enhanced by TLR2 stimulation. Microbes Infect. 2016, 18, 627-638. [CrossRef]

132. Massari, P.; Visintin, A.; Gunawardana, J.; Halmen, K.A.; King, C.A.; Golenbock, D.T.; Wetzler, L.M. Meningococcal porin PorB binds to TLR2 and requires TLR1 for signaling. J. Immunol. 2006, 176, 2373-2380. [CrossRef] 
133. Massari, P.; Henneke, P.; Ho, Y.; Latz, E.; Golenbock, D.T.; Wetzler, L.M. Cutting edge: Immune stimulation by neisserial porins is toll-like receptor 2 and MyD88 dependent. J. Immunol. 2002, 168, 1533-1537. [CrossRef] [PubMed]

134. Massari, P.; Ram, S.; Macleod, H.; Wetzler, L.M. The role of porins in neisserial pathogenesis and immunity. Trends Microbiol. 2003, 11, 87-93. [CrossRef]

135. Yamamoto, M.; Yamazaki, S.; Uematsu, S.; Sato, S.; Hemmi, H.; Hoshino, K.; Kaisho, T.; Kuwata, H.; Takeuchi, O.; Takeshige, K.; et al. Regulation of Toll/IL-1-receptor-mediated gene expression by the inducible nuclear protein IkappaBzeta. Nature 2004, 430, 218-222. [CrossRef]

136. Zughaier, S.M. Neisseria meningitidis capsular polysaccharides induce inflammatory responses via TLR2 and TLR4-MD-2. J. Leukoc. Biol. 2011, 89, 469-480. [CrossRef] [PubMed]

137. Laflamme, N.; Rivest, S. Toll-like receptor 4: The missing link of the cerebral innate immune response triggered by circulating gram-negative bacterial cell wall components. FASEB J. 2001, 15, 155-163. [CrossRef] [PubMed]

138. Laflamme, N.; Soucy, G.; Rivest, S. Circulating cell wall components derived from gram-negative, not gram-positive, bacteria cause a profound induction of the gene-encoding Toll-like receptor 2 in the CNS. J. Neurochem. 2001, 79, 648-657. [CrossRef]

139. Matsushita, K.; Takeuchi, O.; Standley, D.M.; Kumagai, Y.; Kawagoe, T.; Miyake, T.; Satoh, T.; Kato, H.; Tsujimura, T.; Nakamura, H.; et al. Zc3h12a is an RNase essential for controlling immune responses by regulating mRNA decay. Nature 2009, 458, 1185-1190. [CrossRef] [PubMed]

140. Feurer, D.J.; Weller, R.O. Barrier functions of the leptomeninges: A study of normal meninges and meningiomas in tissue culture. Neuropathol. Appl. Neurobiol. 1991, 17, 391-405. [CrossRef]

141. Humphries, H.E.; Triantafilou, M.; Makepeace, B.L.; Heckels, J.E.; Triantafilou, K.; Christodoulides, M. Activation of human meningeal cells is modulated by lipopolysaccharide (LPS) and non-LPS components of Neisseria meningitidis and is independent of Toll-like receptor (TLR)4 and TLR2 signalling. Cell. Microbiol. 2005, 7, 415-430. [CrossRef]

142. Wells, D.B.; Tighe, P.J.; Wooldridge, K.G.; Robinson, K.; Ala' Aldeen, D.A. Differential gene expression during meningeal-meningococcal interaction: Evidence for self-defense and early release of cytokines and chemokines. Infect. Immun. 2001, 69, 2718-2722. [CrossRef]

143. Fowler, M.I.; Weller, R.O.; Heckels, J.E.; Christodoulides, M. Different meningitis-causing bacteria induce distinct inflammatory responses on interaction with cells of the human meninges. Cell. Microbiol. 2004, 6, 555-567. [CrossRef] [PubMed]

144. Robinson, K.; Taraktsoglou, M.; Rowe, K.S.; Wooldridge, K.G.; Ala'Aldeen, D.A. Secreted proteins from Neisseria meningitidis mediate differential human gene expression and immune activation. Cell. Microbiol. 2004, 6, 927-938. [CrossRef] [PubMed]

Publisher's Note: MDPI stays neutral with regard to jurisdictional claims in published maps and institutional affiliations.

(C) 2020 by the authors. Licensee MDPI, Basel, Switzerland. This article is an open access article distributed under the terms and conditions of the Creative Commons Attribution (CC BY) license (http://creativecommons.org/licenses/by/4.0/). 